\title{
SD-Squared: On the Association Between Semantic Dementia and Surface Dyslexia
}

\author{
Anna M. Woollams \\ Medical Research Council Cognition and Brain Sciences Unit
}

\author{
Matthew A. Lambon Ralph \\ University of Manchester
}

\author{
David C. Plaut \\ Carnegie Mellon University
}

\author{
Karalyn Patterson \\ Medical Research Council Cognition and Brain Sciences Unit
}

\begin{abstract}
Within the connectionist triangle model of reading aloud, interaction between semantic and phonological representations occurs for all words but is particularly important for correct pronunciation of lower frequency exception words. This framework therefore predicts that (a) semantic dementia, which compromises semantic knowledge, should be accompanied by surface dyslexia, a frequency-modulated deficit in exception word reading, and (b) there should be a significant relationship between the severity of semantic degradation and the severity of surface dyslexia. The authors evaluated these claims with reference to 100 observations of reading data from 51 cases of semantic dementia. Surface dyslexia was rampant, and a simple composite semantic measure accounted for half of the variance in low-frequency exception word reading. Although in 3 cases initial testing revealed a moderate semantic impairment but normal exception word reading, all of these became surface dyslexic as their semantic knowledge deteriorated further. The connectionist account attributes such cases to premorbid individual variation in semantic reliance for accurate exception word reading. These results provide a striking demonstration of the association between semantic dementia and surface dyslexia, a phenomenon that the authors have dubbed $S D$-squared.
\end{abstract}

Keywords: surface dyslexia, semantic memory, reading aloud, frequency, regularity

Current computational models of normal and disordered reading aloud differ in their architectural, representational, and processing assumptions. There is, however, general agreement that there are at least two procedures involved in the translation of orthography to phonology $(\mathrm{O} \rightarrow \mathrm{P})$, one restricted to whole-word information and the other including or specializing in subword information. This consensus has arisen in part from the need to account for the neuropsychological double dissociation between acquired phono-

Anna M. Woollams and Karalyn Patterson, Medical Research Council (MRC) Cognition and Brain Sciences Unit, Cambridge, United Kingdom; Matthew A. Lambon Ralph, School of Psychological Sciences, University of Manchester, United Kingdom; David C. Plaut, Department of Psychology and Center for the Neural Basis of Cognition, Carnegie Mellon University.

The research reported here was supported by Grant MH64445 from the National Institute of Mental Health Interdisciplinary Behavior Science Center. We are grateful to John Hodges for permission to publish results from those patients under his care; to Jay McClelland and Mark Seidenberg for helpful discussions concerning the issues considered in this article; to Elizabeth Jefferies for contributing data from eight patients; to Naida Graham for contributing age-matched control reading data; and to all of the staff at the MRC Cognition and Brain Sciences Unit involved in collecting and scoring the data reported in this article.

Correspondence concerning this article should be addressed to Anna M. Woollams, MRC Cognition and Brain Sciences Unit, 15 Chaucer Road, Cambridge, CB2 2EF United Kingdom. E-mail: anna.woollams@mrc-cbu .cam.ac.uk logical dyslexia, characterized by a selective deficit in the reading aloud of novel letter strings, and acquired surface dyslexia, hallmarked by a selective deficit in the oral reading of words with atypical or exceptional mappings between spelling and sound. Within current computational models of reading aloud, the selective difficulty with nonword reading in phonological dyslexia is attributed to disruption of some component of the subword pathway (Coltheart, 2006; Harm \& Seidenberg, 2001), whereas the selective difficulty with atypical word reading in surface dyslexia is attributed to disruption of the whole-word pathway (Coltheart, 2006; Patterson et al., 1996). Yet this is as far as the consensus extends-when one considers the specific nature of the $\mathrm{O} \rightarrow \mathrm{P}$ procedure thought to be impaired in surface dyslexia, genuine differences between current computational models of reading aloud emerge.

\section{THEORETICAL PERSPECTIVES ON SURFACE DYSLEXIC READING}

One critical difference between current computational models of reading aloud concerns the extent to which semantic activation of phonology is assumed to be required for the successful pronunciation of words with atypical or exceptional correspondences between spelling and sound. Throughout this article, we consider the two most explicit and contrasting positions on this issue as embodied in the dual-route versus connectionist triangle models of reading aloud. In the dual-route cascaded (DRC) model (Coltheart, Rastle, Perry, Langdon, \& Ziegler, 2001), the nonlexical $\mathrm{O} \rightarrow \mathrm{P}$ 
route contains a system of grapheme-phoneme rules capable of correctly translating nonwords and words with typical or regular mappings between spelling and sound. The direct lexical route allows correct pronunciation of all known words, including lowfrequency exception words, without recourse to semantic information. Hence within the DRC model, correct reading aloud of all known words may be achieved without any knowledge of the meanings of those words, and it is for this reason that the semantic system of the model remains unimplemented. The DRC model therefore predicts no relationship between the occurrence of degraded semantic knowledge and the incidence of surface dyslexia. Specifically, the expectation from a DRC perspective is that intact exception word reading will be observed in some or many patients with impaired semantic knowledge, and that a deficit in exception word reading will predict nothing about the status of a patient's semantic knowledge. Any case of association between semantic impairment and surface dyslexia is interpreted as indicating that brain damage has accidentally compromised the separate areas responsible for lexical and semantic processing, rather than denoting anything theoretically meaningful about the functional architecture of the reading system.

A contrasting view is provided by the connectionist triangle model of reading aloud, depicted in Figure 1 (Harm \& Seidenberg, 2004; Plaut, McClelland, Seidenberg, \& Patterson 1996; Seidenberg \& McClelland, 1989). The architecture of the triangle model incorporates groups of units for the distributed representation of spelling, sound, and meaning. Processing within the model is determined by the weights on connections between these units. The values of these weights are derived from exposure to a representative corpus of monosyllabic words using an errorcorrecting learning algorithm. In a partial implementation of the triangle model, Plaut et al. (1996) demonstrated that in the absence of a semantic system, the $\mathrm{O} \rightarrow \mathrm{P}$ procedure could learn to pronounce both regular and exception words correctly, as well as

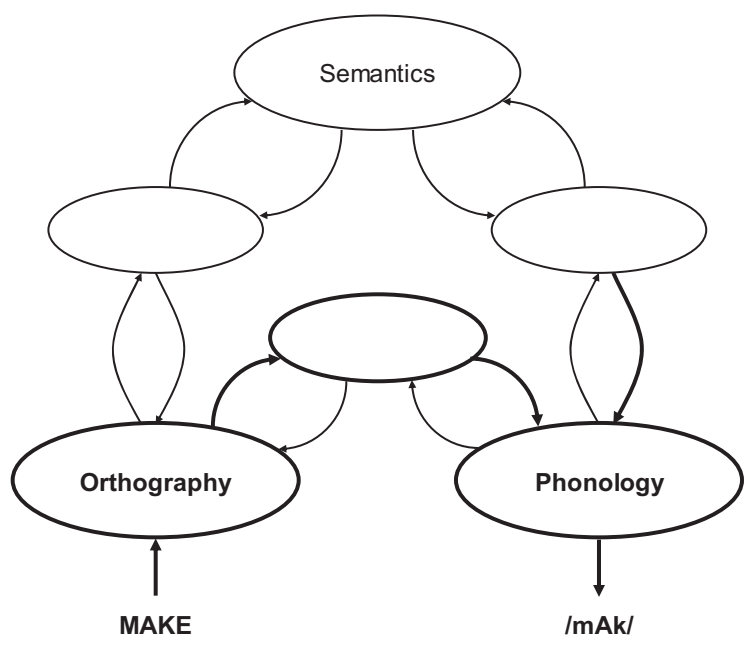

Figure 1. The triangle model of reading aloud. Implemented aspects of the model are shown in bold. Adapted from "Understanding Normal and Impaired Word Reading: Computational Principles in Quasi-Regular Domains" by D. C. Plaut, J. L. McClelland, M. S. Seidenberg, and K. Patterson, 1996, Psychological Review, 103, p. 59. Copyright 1996 by the American Psychological Association. Adapted with permission. generalize to pronounceable nonwords. Yet this demonstration is still compatible with the proposal that in a full implementation of the triangle model that includes semantics, accurate reading aloud of exception words will partially rely on activation from semantics to phonology $(\mathrm{S} \rightarrow \mathrm{P})$.

To investigate this issue, Plaut et al. (1996) performed a simulation in which $\mathrm{O} \rightarrow \mathrm{P}$ was trained in the presence of additional frequency-weighted activation of phonology designed to serve as an approximation of the contribution of semantic information to reading aloud. As there was no implementation of actual semantic representations, we refer to this source of phonological activation as " $\mathrm{S}$ " $\rightarrow \mathrm{P}$. Under these circumstances, a graded division of labor developed within the reading system that functioned to maximize the network's overall efficiency. Specifically, the $\mathrm{O} \rightarrow \mathrm{P}$ pathway specialized in representing the more frequent and/or consistent mappings between orthography and phonology, with correct reading of exception words coming to depend more on " $\mathrm{S}$ " $\rightarrow \mathrm{P}$. This division-of-labor hypothesis has been supported by studies demonstrating that in normal individuals, the impact on reading aloud of a semantic variable, imageability, is confined to low-frequency exception words (Cortese, Simpson, \& Woolsey, 1997; Shibahara, Zorzi, Hill, Wydell, \& Butterworth, 2003; Strain \& Herdman, 1999; Strain, Patterson, \& Seidenberg, 1995, 2002). In addition, this empirical pattern has been successfully simulated by a fuller implementation of the triangle model incorporating a featural semantic system (Harm \& Seidenberg, 2004).

When Plaut et al. (1996) decreased "S" $\rightarrow \mathrm{P}$ activation to emulate the impact of a semantic deficit on reading aloud, performance on exception words was selectively impaired, as seen in surface dyslexia. Moreover, the amount of remaining " $\mathrm{S}$ " $\rightarrow \mathrm{P}$ activation determined the severity of the surface dyslexia, with the deficit observed for low-frequency exception word reading under moderately reduced " $\mathrm{S}$ " $\rightarrow \mathrm{P}$ extending to encompass higher frequency exception words with more extreme removal of this source of activation. As these lesion simulations demonstrate, the triangle model predicts a strong association between degraded semantic knowledge and surface dyslexia and, further, that there should be a close correspondence between the extent of the semantic deficit and the degree of surface dyslexia both across different individuals and for any given individual over time if the semantic deficit is progressive.

As the direct $\mathrm{O} \rightarrow \mathrm{P}$ connections of the triangle model are in fact capable of learning to pronounce exception words correctly, the model allows for the possibility that different individuals may vary in the extent to which processing of these words depends on $\mathrm{S} \rightarrow \mathrm{P}$ activation. Indeed, multiple lesion simulations trained to differ in degree of premorbid reliance on " $\mathrm{S}$ " $\rightarrow \mathrm{P}$ activation demonstrate that variation along this dimension can have predictable consequences for the severity of surface dyslexia (Plaut, 1997). Given that the connectionist approach allows for at least quantitative variation in the functional architecture of the intact reading system, this account therefore predicts individual differences in the degree of semantic damage required to produce surface dyslexia. In other words, (a) despite a strong prediction that appreciable semantic degradation will be associated with surface dyslexia, the triangle model also countenances the occasional observation of a dissociation, and (b) unlike the DRC model, the triangle model treats both associations and dissociations between semantic status and reading 
performance as theoretically meaningful with respect to the functional architecture of the reading system.

To evaluate the triangle model's explicit assumption that accurate exception word reading typically hinges on $\mathrm{S} \rightarrow \mathrm{P}$ activation, in the present article we report the most extensive cross-sectional and longitudinal consideration to date of reading performance in semantic dementia, a condition characterized by relatively selective progressive deterioration of semantic memory. Although both semantic dementia and surface dyslexia can be abbreviated $S D$ (a fact that of course provides the title to this article), we willconsistent with a large literature-refer to the neurodegenerative condition as $S D$ and thus spell out the reading disorder as surface dyslexia. The specific predictions from the triangle model's account of surface dyslexia with reference to the performance of a large group of individuals afflicted by a progressive semantic impairment may be summarized as follows: (a) Impaired semantic knowledge will be strongly associated with surface dyslexia in the full group - that is, there will be a pattern of SD-squared; (b) the extent of the semantic impairment will on the whole predict the severity of the surface dyslexia observed both cross-sectionally and longitudinally; (c) individual differences in premorbid semantic reliance during reading aloud will produce very occasional discrepancies between level of semantic knowledge and accuracy of exception word reading; and (d) the rare observation of preserved exception word reading will be longitudinally temporary, such that further semantic degradation will inevitably result in a surface dyslexic reading pattern for any given individual.

Before turning to the present patient data, we consider how these predictions of the triangle model fare in accounting for previous reports of reading aloud by individuals with brain damage, with specific reference to the integrity of their semantic knowledge. As will be seen, the majority of these reports concern data from single cases, which entails various limitations on their theoretical interpretation, constraints that are overcome by the case-series approach adopted in the present work. The cognitive profile associated with the neurodegenerative condition of SD is briefly described before discussion of the nature of the semantic impairment and its expected consequences for reading aloud. Informed by these considerations, a new triangle-model simulation of the reading aloud performance expected in $\mathrm{SD}$, incorporating individual differences in degree of premorbid semantic reliance, will be provided. To foreshadow our results, the correspondence between model and patient data that we obtain is nothing less than remarkable. We defer our assessment of possible alternative accounts for the observed pattern of patient data until the General Discussion.

\section{Previous Associations Between Word Reading and Meaning}

As noted earlier, the triangle model makes the explicit prediction that brain damage or disease compromising semantic activation of phonology will produce surface dyslexia. The cardinal symptom of surface dyslexia constitutes reading errors in which words with exceptional spelling-sound correspondences are pronounced according to their more typical mappings (e.g., pint pronounced to rhyme with mint). Although these errors are common responses to low-frequency exception words among all surface dyslexic individuals, they may also occur to high-frequency exception words in more severe cases (Behrmann \& Bub, 1992;
Bub, Cancelliere, \& Kertesz, 1985; McCarthy \& Warrington, 1986; Shallice, Warrington, \& McCarthy, 1983). The purest form of surface dyslexia is characterized by a highly selective deficit of exception word reading, in the presence of fluent and accurate reading of regular words and nonwords (Bub et al., 1985; McCarthy \& Warrington, 1986; Shallice \& Warrington, 1980; Shallice et al., 1983). Mixed forms of surface dyslexia in which impaired exception word reading is accompanied by an additional though less severe deficit in the accuracy and/or speed of regular word and/or nonword reading have also been reported (Gold et al., 2005; Hodges, Graham, \& Patterson, 1995; Marshall \& Newcombe, 1973; Shallice \& Warrington, 1980).

Surface dyslexia has been observed in a number of different etiologies, but irrespective of the neurological cause of the disorder, it is apparent that the vast majority of these patients have also demonstrated appreciable impairments to semantic memory on tests such as picture naming and/or word-picture matching. For example, apart from SD, impaired performance on various tests tapping semantic memory has also been reported in the majority of cases of surface dyslexia following cerebrovascular accident or head injury (Behrmann \& Bub, 1992; Bub et al., 1985; Hillis \& Caramazza, 1991, 1995; Patterson \& Behrmann, 1997; Saffran, 1985). Some researchers have demonstrated that impaired semantic knowledge corresponds to exception word errors for the same items (Hillis \& Caramazza, 1991, 1995), and such item-level consistency clearly suggests a meaningful relationship, as assumed within the triangle model. Nonetheless, given differences across studies in terms of the stimuli used to assess reading aloud performance and the variation in both tasks and materials used to assess the extent of the semantic deficit, it is difficult to quantify the strength of the commonly observed association between the presence of surface dyslexia and semantic impairments.

When we turn to studies of surface dyslexic readers suffering from the progressive neurological atrophy that characterizes the degenerative conditions of Alzheimer's disease and SD, the association between surface dyslexia and impairments of semantic memory is even more striking. Again, much of the evidence for this association has been derived from single-case or small caseseries studies (Blazely, Coltheart, \& Casey, 2005; Funnell, 1996; K. S. Graham, Hodges, \& Patterson, 1994; Hillis \& Caramazza, 1995; Marshall \& Newcombe, 1973; McCarthy \& Warrington, 1986; Patterson et al., 1996; Parkin, 1993; Schwartz, Saffran, \& Marin, 1980; Shallice \& Warrington, 1980; Shallice et al., 1983; Ward, Stott, \& Parkin, 2000; Warrington, 1975; Noble, Glosser, \& Grossman, 2000), but some investigations have used larger case series (N. Graham, Patterson, \& Hodges, 2000; Jefferies, Lambon Ralph, Jones, Bateman, \& Patterson, 2004; Patterson, Graham, \& Hodges, 1994; Patterson \& Hodges, 1992; Patterson et al., 2006; Strain, Patterson, Graham, \& Hodges, 1998). Through the use of constant stimuli across different individuals, these case-series investigations enable us to assess the triangle model's prediction that the extent of the semantic impairment will predict the severity of the surface dyslexia observed both cross-sectionally and longitudinally, and they therefore warrant further consideration. We focus on the case-series studies of reading in $\mathrm{SD}$, given that this is the topic under investigation here.

In the first explicit investigation of this issue, Patterson and Hodges (1992) assessed the reading performance of six SD patients on a large set of words known as the "Surface List" (which 
figures prominently in the current study as well), with reference to their scores on tests of semantic knowledge such as picture naming and word-picture matching. In the four cases considered to have moderately degraded semantic knowledge, a selective deficit in exception word reading was apparent for low-frequency items; in the two patients with more severe semantic impairments, reading errors to exception words were even more prevalent for lowfrequency items and occurred to high-frequency items as well. Furthermore, two of the moderate cases were assessed further along in the inexorable semantic deterioration that is the hallmark of $\mathrm{SD}$, and these individuals were reported to have more extensive surface dyslexia (Patterson et al., 1996).

N. Graham et al. (2000) reported that a group of 13 SD patients showed significantly lower accuracy than controls on exception word reading, most pronounced for low-frequency items but also apparent for high-frequency items. Six of the original 13 patients tested at a later stage of disease progression, at which point their performance on tests of semantic knowledge had predictably deteriorated, showed a further decline in accuracy of exception word reading. Exception word reading for the group was significantly related to various measures of semantic knowledge, including picture naming and spoken word-picture matching. Most recently, Patterson et al. (2006) studied 14 SD patients and demonstrated (a) that performance on low-frequency exception word reading fell more than two standard deviations below the mean for agematched controls in every single patient, and (b) that a composite score from nonreading semantic tests correlated strongly with exception word reading success.

In summary, previous research has revealed substantial empirical support for the specific predictions derived from the triangle model, in which impaired semantic knowledge results in a deficit of exception word reading. Irrespective of underlying etiology, impaired semantic knowledge has been strongly associated with the presence of surface dyslexic reading. Case-series studies of progressive neurological disorders, particularly SD, have demonstrated a quantitative relationship between the extent of the semantic impairment and the severity of the surface dyslexia observed, both cross-sectionally and longitudinally. But what of the predictions that individual differences in premorbid semantic reliance during reading aloud should produce occasional dissociations between level of semantic knowledge and accuracy of exception word reading, and that these should be temporary in the case of progressive disorders? To address this issue, we turn to an examination of the small number of previous reports of intact exception word reading among individuals with impaired semantic knowledge, and intact semantic knowledge among individuals with impaired exception word reading.

\section{Previous Dissociations Between Word Reading And Meaning}

Intact exception word reading in the presence of impaired semantic memory has been reported in single-case studies with an etiology of stroke (Gerhand, 2001) and hemorrhage (Miozzo \& Gordon, 2005; Weekes \& Robinson, 1997). The same dissociation has occasionally been observed with Alzheimer's disease (Lambon Ralph, Ellis, \& Franklin, 1995; Noble et al., 2000; Raymer \& Berndt, 1996). Some caution is warranted, however, in the interpretation of the data from these cases, as it is possible that attentional and working memory deficits, combined with the use of multiple-item forced-choice semantic assessments, may result in overestimation of the extent of the true semantic deficits (Jefferies \& Lambon Ralph, 2006; Patterson et al., 2006; Silveri \& Colosimo, 1995).

$\mathrm{SD}$, because of its relatively selective deterioration of semantic knowledge, is less susceptible to this concern, and one of the most widely cited cases of dissociation between semantics and reading occurred in a patient who almost certainly had SD, case W.L.P. (Schwartz, Marin, \& Saffran, 1979; Schwartz et al., 1980). At initial assessment, W.L.P. had a clear semantic deficit yet was unimpaired at high-frequency exception word reading; she was not systematically tested on low-frequency words. When assessed some years later, by which stage her knowledge of meaning had degraded considerably, W.L.P.'s reading of high-frequency exception words had also suffered, now falling into the impaired range. It is therefore possible that other SD patients who initially demonstrate preserved exception word reading in the presence of a semantic deficit will, like W.L.P., develop surface dyslexia with further semantic degradation. Unfortunately, longitudinal data are not available for two more recently reported SD cases with intact low-frequency exception word reading (Blazely et al., 2005; Cipolotti \& Warrington, 1995).

What is perhaps most striking, however, is how few reports there are of intact exception word reading with semantic impairment relative to the many cases of cross-sectional and longitudinal association. Furthermore, the other side of this dissociation coin, namely, intact semantic knowledge in the face of impaired lowfrequency exception word reading, is apparently even rarer, with only two such cases reported in the literature to date. As a consequence of brain injury, N.W. (Weekes \& Coltheart, 1996) demonstrated a pattern of mild surface dyslexia, despite perfect performance on tests of both picture naming and word-picture matching. More recently, a case of SD has been reported in which surface dyslexia was in fact the presenting symptom of the disease (Mendez, 2002). Upon formal assessment, this patient showed impaired reading of exception words, in the presence of slightly impaired picture naming but perfect word-picture matching. Given the progressive nature of $\mathrm{SD}$, previous literature would lead us to expect a continued decline in performance on both semantic and reading measures.

Existing cross-sectional and longitudinal data concerning reading in SD are therefore entirely consistent with both of the triangle model's predictions that (a) the majority of cases will be characterized by an SD-squared pattern even early in semantic decline and (b) differences in premorbid semantic reliance during reading aloud will produce occasional and temporary dissociations between level of semantic knowledge and accuracy of exception word reading. Specifically, those rare cases in which an appreciable semantic impairment co-occurs with intact exception word reading are regarded as reflecting a low degree of premorbid reliance on $\mathrm{S} \rightarrow \mathrm{P}$ activation to sustain accurate exception word reading. Hence, for such individuals, a marked decrement in semantic knowledge will be required before a surface dyslexic reading pattern emerges. Conversely, the even rarer cases in which reasonably intact semantic knowledge co-occurs with a detectable exception word reading deficit are interpreted as indicating a high degree of reliance on $\mathrm{S} \rightarrow \mathrm{P}$ activation to support correct exception word reading premorbidly. As a consequence, even a very mild semantic deficit will be sufficient to produce a surface dyslexic 
reading pattern in such cases, and both semantic and reading performance would be expected to decline in parallel with progression over time. Effectively, the triangle model proposes that what varies across different cases of SD is not the presence of surface dyslexia but rather the level of semantic degradation necessary to produce it.

Although the preceding survey of the existing research concerning reading aloud in SD is concordant with the triangle model's account of surface dyslexia, determining the distribution of the reading performance observed under conditions of semantic impairment is hindered by both the preponderance of single-case studies and their use of different semantic and reading assessments. We now turn to a brief consideration of the manner in which the large-scale case-series methodology used in this study overcomes these limitations.

\section{Case-Series Methodology in Cognitive Neuropsychology}

Traditional cognitive neuropsychology is characterized, and according to some even defined, by a reliance on data from detailed studies of single cases of patients suffering from neurological damage (Caramazza \& McCloskey 1988; Coltheart, 2001; Ellis \& Young, 1988; McCloskey \& Caramazza, 1988). In this context, associations between impairments in different cognitive domains are distrusted, as these may emerge merely from the anatomical contiguity of the damaged brain regions rather than reflecting anything theoretically significant concerning the underlying functional architecture of cognition. Instead, dissociations between impaired and intact patterns of performance have been held to indicate functional independence of the relevant processes. This approach has formed the basis for a large body of research and many conclusions regarding the functional architecture underpinning various aspects of cognition (Rapp, 2001).

Yet with the advent of connectionist models of normal and impaired cognitive performance, it is becoming increasingly apparent that an exclusive focus on single cases and dissociation logic has its own limitations and liabilities. An extensive consideration of this controversial issue falls outside the scope of the present work, and excellent discussions of various aspects of this debate appear elsewhere (Medler, Dawson, \& Kingstone, 2005; Plaut, 1995, 2003; Van Orden, Jansen op de Haar, \& Bosman, 1997; Van Orden, Pennington, \& Stone, 2001). We note here only two key aspects that are of particular relevance to the current study of reading aloud performance in SD. The first is that the preponderance of single-case studies has resulted in variations in the semantic and reading assessments used across different patients. In light of the fact that the presence of an association or a dissociation within any given patient can be determined largely by the relative sensitivity of the assessments used (Ellis \& Young, 1988; Shallice, 1988), such variations can have serious implications within the context of an approach that assigns differential weight to each pattern of performance. The second is that the use of single-case methodology relies on the assumption of invariance between different individuals in terms of the functional architecture of their premorbid reading systems (Coltheart, 2001, 2006). Healthy adult readers do, however, vary in degree of semantic reliance during low-frequency exception word reading, as indicated by differences in the magnitude of the imageability effect when grouped according to their scores on assessments tapping $\mathrm{O} \rightarrow \mathrm{P}$ competency such as nonword reading (Strain \& Herdman, 1999).
Clearly, then, what is needed to assess the specific predictions of the triangle model's account of surface dyslexia is cross-sectional and longitudinal data, from a large number of patients with a selective semantic impairment, derived from consistent assessments of reading aloud and semantic knowledge; that is precisely what the present study provides, in the form of 100 observations of reading from $51 \mathrm{SD}$ patients. The approach adopted here exemplifies case-series methodology, which is becoming increasingly popular within cognitive neuropsychology (Lambon Ralph et al., 2002; Lambon Ralph, Patterson, Graham, Dawson, \& Hodges, 2003; Rogers, Ivanoiu, Patterson, \& Hodges, 2006; Schwartz, Dell, Martin, Gahl, \& Sobel, 2006). Consideration of the performance of a large group of patients enables the researcher to identify both the typical profile for that group and any patients who deviate from it. Hence the case-series approach is particularly suitable for domains in which there is reason to expect that premorbid individual differences will produce variations in performance subsequent to impairment, as in reading aloud. Such individual differences are most readily interpretable when the patients considered form a relatively homogeneous group in terms of their specific neurological damage and its cognitive consequences; with this in mind, we turn to a brief description of SD.

\section{Preservation and Degradation in SD}

SD is a relatively circumscribed disorder of semantic memory that arises as a result of progressive atrophy of the anterior temporal lobes (Hodges, Patterson, Oxbury, \& Funnell, 1992; Mummery et al., 2000; Neary et al., 1998; Nestor, Fryer, \& Hodges, 2006; Snowden, Goulding, \& Neary, 1989). Neuroanatomically, this anterior temporal atrophy is often asymmetrical but always bilateral, especially as the disease progresses (Seeley et al., 2005). Behaviorally, SD patients are generally well oriented in space and time, and although their spoken language is compromised by a marked anomia, it is otherwise phonologically correct, fairly fluent, and largely grammatical (Hodges \& Patterson, 1996; Patterson $\&$ MacDonald, 2006). The selectivity of the semantic memory deficit in SD is highlighted by essentially normal performance on tasks tapping cognitive abilities not requiring knowledge of meaning, such as nonverbal problem solving, visuospatial skills, and attentional capacity (Hodges et al., 1995; Hodges, Patterson, \& Tyler, 1994). Both working memory and episodic memory abilities are also within the normal range on tests using appropriate materials (K. S. Graham, Simons, Pratt, Patterson, \& Hodges, 2000; Jefferies, Jones, Bateman, \& Lambon Ralph, 2004; Knott, Patterson, \& Hodges, 2000).

The pattern of intact performance on nonsemantic tasks in SD contrasts sharply with impairments on any tests requiring access to meaning-level information. The semantic deficit is most apparent on tests of vocabulary production and comprehension, such as picture naming and spoken word-picture matching, and it is these measures that are used to quantify the level of semantic deficit of the patients in this study. Yet it should also be emphasized that the semantic deficit is not restricted to the linguistic domain and clearly affects performance on nonverbal tasks such as picture drawing, visual object recognition, sound recognition, and object use (Bozeat et al., 2003; Bozeat, Lambon Ralph, Patterson, Garrard, \& Hodges, 2000; Bozeat, Lambon Ralph, Patterson, \& Hodges, 2002; Rogers, Hodges, Lambon Ralph, \& Patterson, 2003). 
SD is a most appropriate disorder in which to evaluate the impact of semantic damage on reading performance for a number of reasons. First, SD patients form a relatively homogeneous group in terms of the nature of their impairment and its underlying neurological cause. Second, the specificity of the semantic deficit means that any associated difficulties in word reading are unlikely to be the result of other, nonsemantic impairments, particularly of visual or phonological processing (Cumming, Patterson, Verfaellie, \& Graham, 2006; Jefferies, Jones, Bateman, \& Lambon Ralph, 2005). Third, the progressive nature of the disorder allows an assessment of word reading performance across a wide range of semantic abilities in two ways: (a) Different individuals will vary in the severity of their semantic deficit according to their stage of disease progression, allowing for extensive cross-sectional comparisons, and (b) the same individuals will evidence an inevitable decline in their semantic ability over time, enabling additional longitudinal considerations that are particularly informative with respect to premorbid individual differences in semantic reliance during reading aloud.

To quantify the predictions of the triangle model concerning the incidence and severity of surface dyslexia expected across a broad range of semantic degradation, we first present a new simulation of the impact of reduced " $\mathrm{S}$ " $\rightarrow \mathrm{P}$ activation on reading aloud within the triangle model of Plaut et al. (1996). The motivation for conducting this new simulation was threefold. First, reading performance by the network was assessed using the same stimulus words (the Surface List) used to test the SD patients. Second, the lesion simulation results were derived from multiple versions of the network trained with varying levels of " $\mathrm{S}$ " $\rightarrow \mathrm{P}$ activation in order to approximate the hypothesized variation that arises owing to premorbid differences in semantic reliance during reading aloud. Third, although this particular network still contains no true implementation of the semantic system, the lesioning technique was supplemented in order to provide a closer approximation to the impact of degraded meaning on the activation of phonology in reading aloud, informed by consideration of the nature of the semantic degradation observed in SD.

\section{Implications of Semantic Degradation for Word Reading}

Although the precise nature of the semantic degradation in SD is not the focus of the present work, it is in fact germane to the question of how to simulate surface dyslexia in the triangle model. Consider the profile of object/picture-naming performance in SD, assessed both cross-sectionally and longitudinally (e.g., Hodges et al., 1995; Lambon Ralph, Graham, Ellis, \& Hodges, 1998; Lambon Ralph, McClelland, Patterson, Galton, \& Hodges, 2001; Rogers, Lambon Ralph, Garrard, et al., 2004). First of all, success is always strongly predicted by some (or indeed any) measure of object and name familiarity or frequency (K. S. Graham et al., 1994; Lambon Ralph et al., 1998). Second, the most common error type in naming at all stages of SD, and increasingly so with progression, is a failure to respond ("I don't know"). Third, despite the prevalence of omissions, errors of commission do occur. The most common of these are superordinate responses (e.g., goat $\rightarrow$ "animal") and category coordinate responses in which the incorrect name given is a more frequent and/or more prototypical instance of the category than the target (e.g., goat $\rightarrow$ "dog"). As conceptual knowledge declines, coordinate responses initially increase and then decline, with a corresponding increase in superordinate responses (Rogers, Lambon Ralph, Garrard, et al., 2004).
Object-naming errors represent a good-or, in any case, perhaps the best available - index of the nature of semantic activation of phonology. The errors of commission establish that $\mathrm{S} \rightarrow \mathrm{P}$ activation in SD is not simply diminished; on at least some occasions, there is sufficient $\mathrm{S} \rightarrow \mathrm{P}$ activation for the patient to produce a response, but one that is less specific or precise than the correct response. With respect to reading aloud, the upshot of "rogue" phonological activation of nonspecific or inaccurate alternatives for a written word's referent is that additional variability is introduced into the computation of pronunciation. For example, if presentation of the written word goat activates a semantic pattern indistinguishable from that of a dog or indeed a generic animal (Rogers, Lambon Ralph, Garrard, et al., 2004), then there will necessarily be some $\mathrm{S} \rightarrow \mathrm{P}$ activation that conflicts with the $\mathrm{O} \rightarrow \mathrm{P}$ computation.

The extent to which the less specific or incorrect $\mathrm{S} \rightarrow \mathrm{P}$ activation in SD will affect the accuracy of both picture naming and reading aloud is, in part, a function of two factors concerning the adjustment of connection weights during training. First, familiar concepts have stronger within-level connections between the semantic units that participate in their representation and hence are less susceptible to the effects of damage (Rogers, Lambon Ralph, Garrard, et al., 2004). Second, familiar concepts tend to be high in spoken word frequency, and therefore $\mathrm{S} \rightarrow \mathrm{P}$ activation for such items will occur more efficiently by virtue of their stronger between-level connections (Lambon Ralph et al., 2001). With these observations in hand concerning the putative nature of semantic degradation in SD and its likely influence on the computation of phonology from print, we can now turn our attention to the modified simulation of the impact of compromised " $\mathrm{S}$ " $\rightarrow \mathrm{P}$ activation on reading aloud for multiple versions of the Plaut et al. (1996) network that vary in the extent of their premorbid division of labor between the direct and semantic pathways.

\section{READING ALOUD IN SD}

\section{A Connectionist Simulation}

This lesion simulation used the feed-forward architecture applied in the original division-of-labor simulations of Plaut et al. (1996, Simulation 4), depicted in Figure 2. The weights on connections between units are derived from training with a large corpus of monosyllabic words, with exposure proportional to the square root of actual written word frequencies. Although the initial random weights on connections between units differed from those in the original simulation, all other aspects of the model's architecture and training are identical to those used in Plaut et al. (1996, Simulation 4), and readers are referred to that article for further details. For present purposes, the most salient aspect of the network's training regime is the gradual introduction of external input to the phonological units, as depicted in Figure 3. This additional source of phonological activation is intended to approximate the increasing contribution of semantic activation that occurs over time in the course of reading development. As can be seen in Figure 3, the magnitude of the " $\mathrm{S}$ " $\rightarrow \mathrm{P}$ activation during training is determined by the log Kučera and Francis (1967) written frequency of each word, reflecting the assumption of stronger semantic representations for higher frequency concepts.

To incorporate some approximation of variation in terms of premorbid semantic reliance into the current lesion simulation, we 
created multiple instantiations of the intact network that differed only in terms of the strength of the frequency weighted " $\mathrm{S}$ " $\rightarrow \mathrm{P}$ activation supplied during training, following the method used by Plaut (1997). The strength of the frequency weighted " $S$ " $\rightarrow P$ activation for each network is determined by the parameter $g$, which denotes its asymptotic level. In the original division-oflabor network presented by Plaut et al. (1996, Simulation 4), $g$ was set at a value of 5, which can be taken as a moderate level of semantic reliance. In the present simulations, five different versions of the network were created by varying $g$ from 3 to 7 , with each version initialized with the same set of random weights. ${ }^{1}$ The difference between the versions of the network in the strength of the frequency weighted " $\mathrm{S}$ " $\rightarrow \mathrm{P}$ activation for low-frequency words over training can be seen in Figure 4. These values were chosen in order to capture a reasonable spread of premorbid semantic reliance, and although more extreme values are certainly possible, these were not explicitly investigated here. In the results that follow, the statistical analyses are conducted on the basis of values that are obtained through weighting the contribution of each version of the network such that we obtained a normal distribution of $g$. Effectively, this weighting equates to a data set containing a single instance of the $g 2 / 7$ versions, two instances of the $g 3 / 6$ versions, and three instances of the $g 5$ version. This weighting procedure is intended to reflect our assumption that extreme variations in degree of semantic reliance among normal healthy adults should be relatively uncommon, as suggested by the low incidence of dissociations in the previous literature. Statistical analyses conducted on the unweighted data yielded a similar pattern of significant results.

\section{Method}

\section{Lesioning}

Once the five versions of the intact network had experienced the frequency-weighted " $\mathrm{S}$ " $\rightarrow \mathrm{P}$ activation for 2000 training epochs, they were subjected to semantic lesions of varying severity in order to simulate the reading aloud performance expected in SD. It

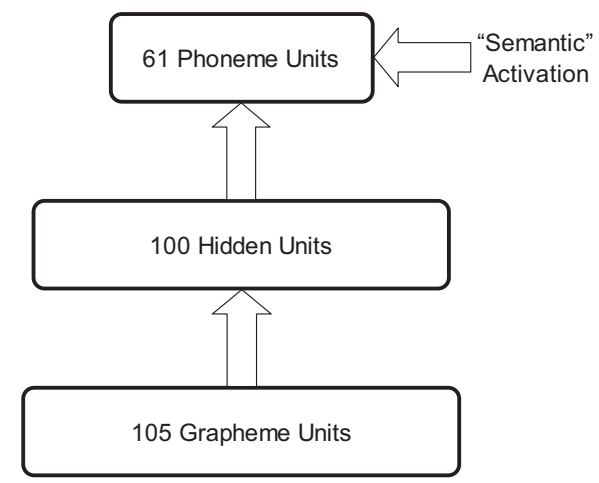

Figure 2. The feed-forward network architecture of the model used in both the original division-of-labor simulations and the current study. Adapted from "Understanding Normal and Impaired Word Reading: Computational Principles in Quasi-Regular Domains" by D. C. Plaut, J. L. McClelland, M. S. Seidenberg, and K. Patterson, 1996, Psychological Review, 103, p. 67. Copyright 1996 by the American Psychological Association. Adapted with permission.

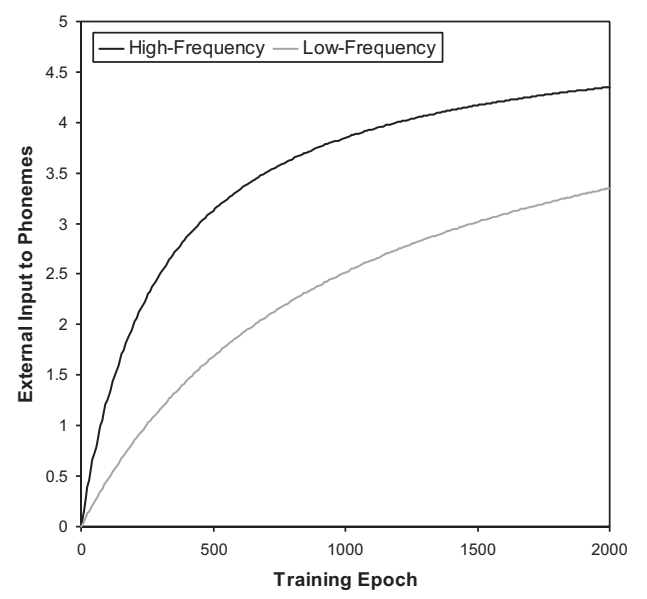

Figure 3. The magnitude of the external input to phonology provided over the course of training within the network for moderate level of semantic strength $(g=5)$ as a function of training epoch and frequency for the average values of the high-frequency (804/million) and low-frequency (5.6/million) words from the Surface List.

is at this point that the method diverged from that used by Plaut et al. (1996, Simulation 4). In the original version, the semantic lesion consisted of a gradual reduction in the amount of " $\mathrm{S}$ " $\rightarrow \mathrm{P}$ input. This diminution is consistent with SD patients' many omission errors in picture naming, and it was therefore also used in the present simulation. As outlined earlier, however, the patients also make errors of commission in naming. Such errors suggest that - in a reading model with implemented semantic representations - the $\mathrm{S} \rightarrow \mathrm{P}$ activation would often be more consistent with a response that is incorrect for the written target word, thus introducing noise into the process of computing the reading response. We simulated this idea in the present study by the addition of Gaussian noise to the " $\mathrm{S}$ " $\rightarrow \mathrm{P}$ activation as it was reduced. The standard deviation of the noise applied was twice the inverse of each word's normalized frequency (i.e., $2 *\left[1-f_{i}\right]$, where $f_{i}$ is the normalized square-root frequency of word $i$ used during training). Hence, the proportional amount of noise delivered to phonology decreased with increasing word frequency. ${ }^{2}$

\section{Stimuli}

The stimuli used to assess the word reading performance of the model were from the Surface List (Patterson \& Hodges, 1992) and are provided in Appendix A. The Surface List consists of a factorial combination of frequency and regularity, with 42 items per cell. Within each level of frequency, the regular and exception items are matched on initial phoneme and do not differ according to Kučera and Francis (1967) written frequency: high-frequency regular $(\mathrm{HR})=811.43$, high-frequency exception $(\mathrm{HE})=798.83$, $t(80)<1$; low-frequency regular $(\mathrm{LR})=5.78$, low-frequency

\footnotetext{
${ }^{1}$ The code for the five trained and intact versions of the network can be downloaded from http://www.cnbc.cmu.edu/ plaut/Woollams -SDsquared/

2 The code used for the lesion simulations can be downloaded from http://www.cnbc.cmu.edu/ plaut/Woollams-SDsquared/
} 


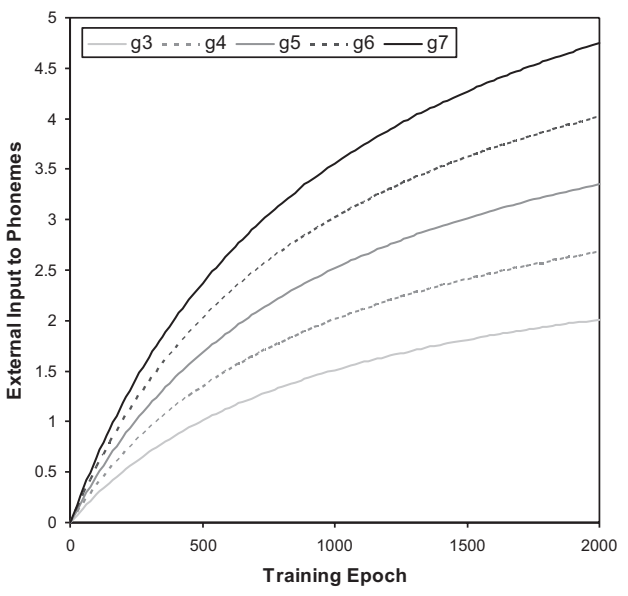

Figure 4. The magnitude of the external input to phonology provided over the course of training within the five versions of the network for low-frequency words (5.6/million) as a function of training epoch and semantic strength $(g)$.

exception $(\mathrm{LE})=5.41, t(78)<1$; or orthographic length: HR $=$ $4.14, \mathrm{HE}=4.24, t(1,82)<1 ; \mathrm{LR}=4.83, \mathrm{LE}=4.81, t(82)<1$. An additional set of 40 novel letter strings, provided in Appendix $\mathrm{B}$, was used to assess the nonword reading performance of the model, with responses scored according to the acceptable pronunciations listed. These word and nonword lists are the same stimuli used to assess the reading performance of the SD patients to be considered in the next section.

\section{Results}

\section{Word Reading}

The accuracy of the network's reading was assessed according to the match between the pronunciation generated by the network and the correct pronunciation of the word (for details, see Plaut et al., 1996) at various points during the gradual reduction of " $\mathrm{S}$ " $\rightarrow \mathrm{P}$ activation. Of course, the relationship between a word's phonological form and its meaning is arbitrary, whereas the correspondence between a word's orthographic and phonological forms is quasi-regular. As a result, the semantic activation required for accurate performance in reading aloud may not be all that substantial relative to that necessary for correct object naming, where all of the activation arises from the $\mathrm{S} \rightarrow \mathrm{P}$ mapping alone. In essence, the semantic activation required for accurate reading aloud of an atypical word needs only to be sufficient to tip the balance of existing phonological activation in favor of the target pronunciation relative to the other alternatives generated by $\mathrm{O} \rightarrow \mathrm{P}$ (e.g., for blood, the correct pronunciation rhyming with mud and the incorrect ones rhyming with good and food). Hence, within the model, " $\mathrm{S}$ " $\rightarrow \mathrm{P}$ activation must be reduced substantially before any form of reading deficit emerges. In the present work, all analyses considered performance of the model for 12 levels of severity when " $\mathrm{S}$ " $\rightarrow \mathrm{P}$ activation was at 3 or below, as this was the lowest asymptotic amount of " $\mathrm{S}$ " $\rightarrow \mathrm{P}$ activation provided to any version of network during training. In line with the analysis of the SD patient data to follow, each observation was treated as independent for the purposes of the main cross-sectional analysis. The overall accuracy of reading performance, averaged across the five versions of the network for each of the 12 levels of lesion severity, is presented in Figure 5A in order to illustrate the general pattern of performance across the four different conditions.

Overall accuracy. The individual observations deriving from the weighted distribution for all versions of the network are presented in Figure 6A for each condition as a function of lesion severity. These data were analyzed using a repeated measures analysis of variance (ANOVA) in which frequency and regularity were entered as within-subject factors and lesion severity was included as an independent linear predictor. The results showed strong effects of frequency, $F(1,106)=1,293.83, p<.0005$, and
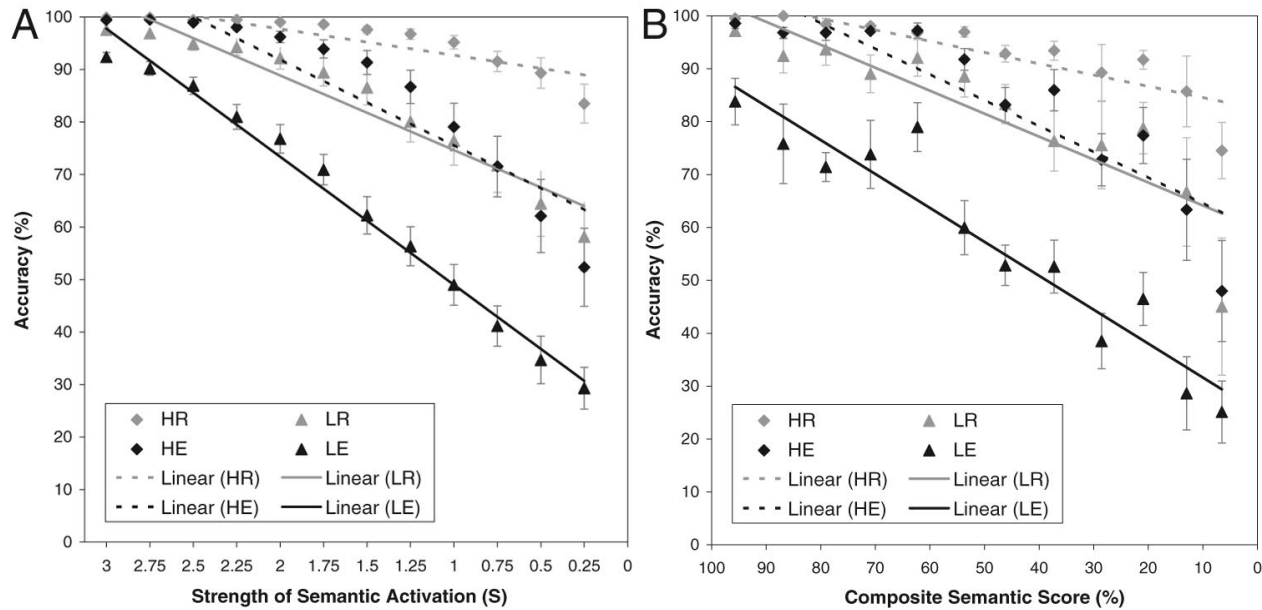

Figure 5. Overall accuracy results for all conditions of the Surface List: (A) for the triangle model simulation for all versions of the network, averaged by lesion severity; and (B) for 100 observations of reading performance from 51 semantic dementia patients, averaged by level of semantic knowledge. Error bars represent standard errors. HR = high-frequency regular words; LR = low-frequency regular words; HE = high-frequency exception words; $\mathrm{LE}=$ low-frequency exception words. 

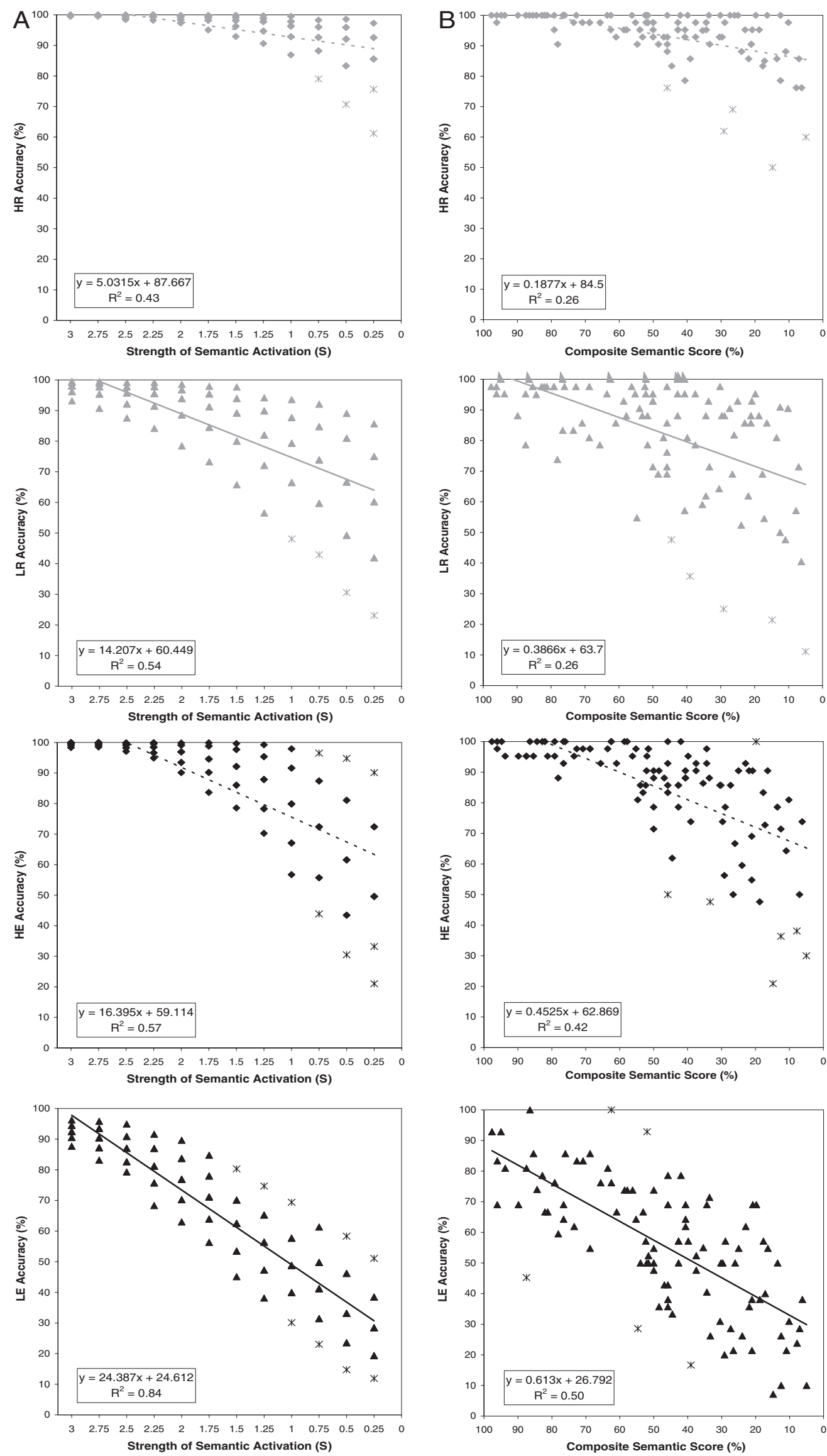
regularity, $F(1,106)=2,030.28, p<.0005$, and a Frequency $\times$ Regularity interaction, $F(1,106)=10.64, p=.001$, reflecting the larger impact of frequency on exception than on regular words and the larger impact of regularity on low- than on high-frequency words. This pattern of interaction was equally apparent across all levels of lesion severity, $F(1,106)<1$. Overall then, the pattern of reading aloud displayed by the network resembled that commonly observed in surface dyslexia.

Lesion severity significantly predicted accuracy of reading aloud for all word types, $F(1,106)=214.05, p<.0005$. The degree of correspondence between lesion severity and reading performance is reflected in the slope of the regression lines provided for each stimulus condition in Figure 6A: for HR, $B=5.03$, $t(106)=8.90, p<.0005$; for LR, $B=14.21, t(106)=11.24, p<$ .0005 ; for HE, $B=16.40, t(106)=11.75, p<.0005$; for LE, $B=$ $24.39, t(106)=23.45, p<.0005$. As is apparent in the slopes of these regression lines, the relationship between lesion severity and reading performance was stronger for low- than for high-frequency words, $F(1,106)=338.89, p<.0005$, and stronger for exception than for regular words, $F(1,11)=769.43, p<.0005$.

Outliers, defined as observations with standardized residuals of \pm 2 , are indicated in Figure $6 \mathrm{~A}$ by asterisks. Accuracy of reading performance fell below that predicted according to strength of semantic activation for four observations among high-frequency regular words (three from $g 7$ and one from $g 6$ ), four observations among low-frequency regular words (all from $g 7$ ), four observations among high-frequency exception words (three from $g 7$ and one from $g 6$ ), and four observations among low-frequency exception words (all from $g 7$ ). Accuracy of reading performance fell above that predicted according to semantic activation for three observations among the high-frequency exception words (all from g3) and for five observations among the low-frequency exception words (all from $g 3$ ). Across all conditions, the number of outliers obtained approximates the $5 \%$ that would be expected if the observations were randomly drawn from a population with a normal distribution of reading accuracy, in line with our technique of weighting the different versions of the network according to a slightly platykurtic normal distribution (kurtosis $=-0.286$ ).

Legitimate alternative reading of components errors. Given that surface dyslexic reading is defined not only by a particular tendency to err on exception words but also by the specific manner in which these are misread, it is naturally of interest to consider the types of errors that occur in this new simulation involving the addition of noise to the " $\mathrm{S}$ " $\rightarrow \mathrm{P}$ activation as this source of input is reduced. In keeping with a commitment to the importance of graded consistency of spelling-to-sound correspondences at multiple subword levels, we do not restrict the errors of interest to traditionally defined regularization errors (i.e., application of the most frequent correspondence between individual graphemes and phonemes) but rather focus on a somewhat broader class of incorrect responses called legitimate alternative reading of components
(LARC) errors (Patterson, Suzuki, Wydell, \& Sasanuma, 1995). A LARC error is defined as a response in which the orthographic components of the stimulus are pronounced in accordance with correspondences contained in another existing monosyllabic word. Thus, for example, the pronunciation of blood to rhyme with either food or good would count as a LARC error. Furthermore, although LARC errors are most likely for exception words, such errors can also occur to regular but inconsistent words (e.g., food to rhyme with good or blood). In the present study, pronunciations containing an alternative body-rime correspondence were considered LARC errors, as were pronunciations involving an alternative grapheme-phoneme correspondence for the few words that possessed a unique orthographic body. The responses accepted as LARC errors for each item are presented in Appendix A. The same criteria were used to classify error types by the connectionist network described in this section and the SD patients to be considered in the next section.

For each observation of reading data from all sampled versions of the network, the proportion of responses constituting LARC errors was computed. The percentages of LARC errors produced by the model are presented in Figure 7A for each condition as a function of lesion severity. These data were analyzed using a repeated measures ANOVA in which frequency and regularity were entered as within-subject factors and lesion severity was included as an independent linear predictor. The results showed strong effects of frequency, $F(1,106)=10.12, p=.002$, and regularity, $F(1,106)=1,587.72, p<.0005$, and a Frequency $\times$ Regularity interaction, $F(1,106)=5.92, p=.017$, reflecting the larger impact of frequency on exception than on regular words and the larger impact of regularity on low- than on high-frequency words. This pattern of interaction was equally apparent across all levels of lesion severity, $F(1,106)=2.29, p=.133$. Hence the pattern of LARC errors produced by the network corresponded to that usually seen in surface dyslexia.

Lesion severity significantly predicted occurrence of LARC errors for all conditions, $F(1,106)=620.08, p<.0005$. The degree of correspondence between lesion severity and occurrence of LARC errors is reflected in the slope of the regression lines provided for each stimulus condition in Figure 7A: for HR, $B=$ $-0.88, t(106)=-13.27, p<.0005$; for LR, $B=-1.09, t(106)=$ $-25.72, p<.0005$; for HE, $B=-13.26, t(106)=-11.06, p<$ .0005 ; for LE, $B=-9.17, t(106)=-30.57, p<.0005$. As is apparent in the slopes of these regression lines, the relationship between lesion severity and occurrence of LARC errors is stronger for exception than for regular words, $F(1,11)=769.43, p<.0005$, but in contrast to the analysis of overall accuracy, the strength of the relationship did not vary according to frequency, $F(1,106)<1$.

\section{Nonword Reading}

In keeping with the original Plaut et al. (1996) simulations, it was assumed that nonwords do not elicit any appreciable semantic

Figure 6 (opposite). Overall accuracy results for each condition of the Surface List: (A) for the triangle model simulation for all versions of the network, according to lesion severity; and (B) for 100 observations of reading performance from 51 semantic dementia patients according to level of semantic knowledge. Observations represented by an asterisk are those cases with standardized residuals greater than 2 . HR $=$ high-frequency regular words; $\mathrm{LR}=$ low-frequency regular words; $\mathrm{HE}=$ high-frequency exception words; LE = low-frequency exception words. 

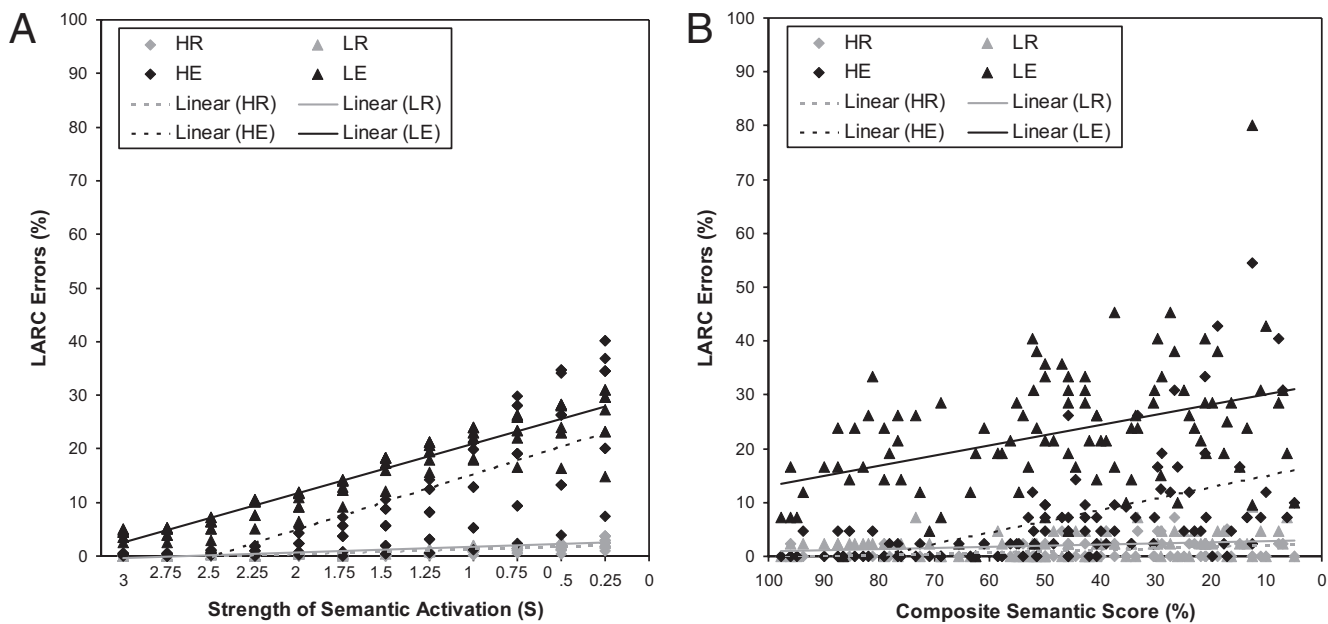

Figure 7. Legitimate alternative reading of components (LARC) error rate results for all conditions of the Surface List: (A) for the triangle model simulation for all versions of the network, according to lesion severity; and (B) for 100 observations of reading performance from 51 semantic dementia patients according to level of semantic knowledge. HR = high-frequency regular words; LR = low-frequency regular words; HE = high-frequency exception words; LE = low-frequency exception words.

activation to transmit to phonology, and therefore neither " $\mathrm{S}$ " $\rightarrow \mathrm{P}$ activation nor its perturbation by noise was applied during processing of novel letter strings. Hence the premorbid performance of the five versions of the network in pronouncing the nonwords in Appendix B $(M=91.11 \%, S D=8.94)$ was unaffected by lesioning.

\section{Summary}

This new simulation offers clear predictions for the pattern of reading aloud to be expected in SD. The SD patients should show significant effects of word frequency and regularity and an interaction between them that remains largely constant across all levels of semantic damage. All word types should bear a significant relationship to level of semantic knowledge, with the relationship being stronger for low- than for high-frequency words and for exception than for regular words. With decreasing semantic knowledge, an increase in LARC errors should be most apparent for exception words, irrespective of frequency. Finally, nonword reading accuracy should not systematically correspond to level of semantic knowledge. In the next section, we test these predictions.

\section{An Empirical Evaluation}

The bulk of the present data set was derived from MemBrain, our patient database in Cambridge. The analysis included every observation of Surface List reading recorded in MemBrain from a patient with an unambiguous clinical diagnosis of SD, provided that the reading data were accompanied by scores on our tasks of picture naming and spoken word-picture matching (WPM) for that patient obtained within 6 months of the reading test. ${ }^{3}$ Some patients had only one entry in MemBrain that met this requirement, whereas others, studied longitudinally, had multiple entries. From this potential set, one patient was excluded because his naming scores early on were inflated by his constant practice in naming these items as part of a rehabilitation study (K. S. Graham, Patter- son, Pratt, \& Hodges, 1999, 2001); for two other patients, the last few observations were excluded because their naming scores had reached zero by this stage of decline; and for one patient, his final score was removed owing to performance for the high-frequency regular words falling below 50\%, suggesting a possible orthographic processing impairment. This selection procedure on MemBrain (for patients seen and diagnosed in the Cambridge clinic) resulted in 88 observations from 43 patients. These were then supplemented with 12 observations from 8 SD patients (seen at a clinic in Bath) who were being tested on the same reading and semantic measures. The final data set for analysis consisted of 100 observations of Surface List reading with accompanying naming and WPM scores, collected between 1991 and 2006, from 51 SD patients.

\section{Method}

\section{Participants}

Given the large number of patients considered in the present analysis, it is obviously not possible to present individual case descriptions. Many of the patients have appeared in previous articles from our research group addressing various aspects of SD (e.g., N. Graham et al., 2000; Hodges, Patterson, et al., 1992; Jefferies, Lambon Ralph, et al., 2004; Patterson et al., 2006; Rogers, Lambon Ralph, Hodges, \& Patterson, 2004). When there is reason to refer to a specific observation, we do so by providing the patient's initials followed by the number of that patient's testing round from which the observation was derived (e.g., J.P.4). As already mentioned, the number of observations per patient was variable: Of the 51 cases, there was a single observation for $n=$ 24 cases, two observations for $n=20$, three for $n=1$, four for $n=$ 1 , five for $n=2$, six for $n=2$, and seven for $n=1$ faithful case.

\footnotetext{
${ }^{3}$ Readers wishing to access a copy of these data should make their requests to Karalyn Patterson: karalyn.patterson@mrc-cbu.cam.ac.uk
} 
It should be noted that patients were not necessarily assessed on reading at every testing round, with the result that two consecutive observations of reading may not derive from two consecutive testing rounds. Thus, if we mention how reading declined from J.P.1 to J.P.4, this means that J.P. did not do the reading test on Rounds 2 and 3. Our administration of the Surface List is divided into four blocks, with roughly equal numbers of the four word classes in each block. Six of the 100 observations of Surface List reading were based on fewer than the full four blocks; their inclusion seems justified on the basis of the high split-half reliability observed for this test when computed across all other observations (Cronbach's $\alpha$ : HR $=.94 ; \mathrm{LR}=.92 ; \mathrm{HE}=.92$; $\mathrm{LE}=.93)$.

Table 1 provides demographic information and summarizes the performance of the patients on a variety of general neuropsychological tests along with the semantic and reading measures used for analysis in this study, which have been converted into percentage values. These results have been divided into four groups of 25 observations each, according to severity of the semantic impairment, defined as the average of the picture naming and WPM scores. For each observation of semantic and reading test data, scores were taken for each neuropsychological test that was administered in the same testing round. Scores for all of the tests presented in Table 1 were not always available for every testing round; hence the number of observations contributing to each value is also provided. Test scores for each severity group that fall more than two standard deviations below the control mean $(n=$ 24-100; mean age $=67-70$ ) are presented in bold.

The relative selectivity of the semantic impairment is immediately apparent in Table 1. Scores on the Mini-Mental State Examination (Folstein, Folstein, \& McHugh, 1975) were below the control range for all groups, as would be expected given that this test assesses some aspects of linguistic ability in addition to orientation, registration, attention/calculation, and recall, but nonverbal intelligence remained high, as indicated by the stability of performance on Raven's Coloured Progressive Matrices (Raven, 1962). Visuoperceptual processing was unaffected even in the severe group, as indicated by scores within the normal range for all groups on the Rey Immediate Copy Test (Lezak, 1976) and the Object Matching subtest of the Birmingham Object Recognition Battery (Riddoch \& Humphreys, 1993). Short-term memory performance on the Wechsler Adult Intelligence Scale Digits Forward and Backward (Wechsler, 1987) was within the normal range across all groups. New learning/episodic memory as assessed by the two subtests (words and faces) of the Recognition Memory Test (Warrington, 1984) was only mildly impaired in three of the four groups for faces but, unsurprisingly, showed deteriorating performance with severity for words. There was a marked and progressive impairment across all groups on tests tapping semantic memory. Deficits in semantically generated output are apparent on

Table 1

Demographic Information and Neuropsychological Test Scores Associated With Each of the 100 Observations of Reading Data From Semantic Dementia Patients Included in the Present Study, Grouped According to Severity

\begin{tabular}{|c|c|c|c|c|c|c|c|c|c|c|c|c|c|}
\hline \multirow[b]{2}{*}{ Assessment } & \multirow[b]{2}{*}{ Maximum } & \multicolumn{3}{|c|}{ Mild } & \multicolumn{3}{|c|}{ Mild-moderate } & \multicolumn{3}{|c|}{ Moderate-severe } & \multicolumn{3}{|c|}{ Severe } \\
\hline & & $n$ & $M$ & $S D$ & $n$ & $M$ & $S D$ & $n$ & $M$ & $S D$ & $n$ & $M$ & $S D$ \\
\hline \multicolumn{14}{|l|}{ Demographic } \\
\hline Age & & 25 & 62 & 7 & 25 & 66 & 8 & 25 & 63 & 8 & 25 & 66 & 6 \\
\hline Education & & 23 & 12 & 2 & 23 & 11 & 3 & 24 & 11 & 2 & 22 & 13 & 3 \\
\hline \multicolumn{14}{|l|}{ General cognitive status } \\
\hline MMSE & 30 & 21 & 26 & 4 & 22 & 21 & 6 & 20 & 21 & 6 & 20 & 14 & 6 \\
\hline Raven's Coloured Matrices & 36 & 9 & 30 & 7 & 13 & 29 & 4 & 12 & 30 & 6 & 11 & 27 & 7 \\
\hline \multicolumn{14}{|l|}{ Perception } \\
\hline Rey Immediate Copy & 36 & 23 & 31 & 7 & 24 & 31 & 7 & 23 & 30 & 9 & 21 & 30 & 8 \\
\hline BORB Object Matching & 40 & 9 & 37 & 2 & 11 & 34 & 4 & 14 & 34 & 6 & 5 & 34 & 6 \\
\hline \multicolumn{14}{|l|}{ Episodic memory } \\
\hline Digit Span Forward & & 21 & 6 & 1 & 24 & 6 & 1 & 22 & 6 & 1 & 22 & 6 & 1 \\
\hline Digit Span Backward & & 21 & 4 & 2 & 24 & 4 & 1 & 21 & 4 & 1 & 21 & 4 & 2 \\
\hline RMT Faces & 50 & 17 & 36 & 6 & 15 & 40 & 6 & 11 & 36 & 9 & 2 & 36 & 8 \\
\hline RMT Words & 50 & 18 & 41 & 6 & 10 & 38 & 4 & 7 & 33 & 4 & 2 & 29 & 4 \\
\hline \multicolumn{14}{|l|}{ Semantic memory } \\
\hline Category Fluency ( 8 categories) & & 21 & 48 & 26 & 23 & 18 & 12 & 18 & 19 & 11 & 13 & 7 & 4 \\
\hline Picture Naming (\%) & 100 & 25 & 70 & 15 & 25 & 27 & 10 & 25 & 14 & 8 & 25 & 5 & 4 \\
\hline Spoken WPM (\%) & 100 & 25 & 95 & 4 & 25 & 81 & 11 & 25 & 62 & 14 & 25 & 29 & 11 \\
\hline PPT Words (\%) & 100 & 18 & 87 & 8 & 16 & 76 & 10 & 19 & 68 & 12 & 8 & 57 & 5 \\
\hline PPT Pictures (\%) & 100 & 23 & 86 & 11 & 22 & 80 & 11 & 22 & 67 & 13 & 16 & 61 & 10 \\
\hline \multicolumn{14}{|l|}{ Reading aloud } \\
\hline High-frequency regular (\%) & 100 & 25 & 99 & 2 & 25 & 96 & 4 & 25 & 93 & 8 & 25 & 88 & 12 \\
\hline Low-frequency regular (\%) & 100 & 25 & 94 & 7 & 25 & 89 & 11 & 25 & 81 & 18 & 25 & 73 & 24 \\
\hline High-frequency exception (\%) & 100 & 25 & 96 & 5 & 25 & 93 & 8 & 25 & 83 & 12 & 25 & 64 & 21 \\
\hline Low-frequency exception (\%) & 100 & 25 & 75 & 14 & 25 & 64 & 17 & 25 & 51 & 16 & 25 & 34 & 18 \\
\hline Nonwords $(\%)$ & 100 & 9 & 82 & 17 & 6 & 70 & 29 & 11 & 84 & 19 & 8 & 74 & 28 \\
\hline
\end{tabular}

Note. Severity was determined on the basis of a composite score derived from picture naming and spoken word-picture matching. Values in bold are those that fall more than 2 standard deviations below the control mean. MMSE = Mini-Mental State Examination; BORB $=$ Birmingham Object Recognition Battery; RMT $=$ Recognition Memory Test; WPM $=$ word-picture matching; PPT $=$ Pyramids and Palm Trees Test. 
the universally impaired and steadily declining Category Fluency Test (Hodges, Salmon, \& Butters, 1992), in which patients are asked to generate as many examples as they can in 1 min each for eight semantic categories. Performance was outside the control range for all groups on both our Cambridge Picture Naming and Spoken WPM tests (Bozeat et al., 2000; Hodges, Salmon, \& Butters, 1992) and the Pyramids and Palm Trees Test (Howard \& Patterson, 1992), reflecting the progressive anomia and declining comprehension that are key features of SD. In summary, Table 1 demonstrates that the reading data to be considered in this study were derived from a group of patients with the relatively selective deterioration in semantic knowledge characteristic of SD.

\section{Stimuli}

The stimuli used to assess the reading performance of the patients were from the Surface List (Patterson \& Hodges, 1992), also used to assess the connectionist network described earlier, and provided in Appendix A. For a subset of 34 observations, nonword reading data from the 40-item list reproduced in Appendix B were available, with patients' responses scored according to the acceptable pronunciations listed.

\section{Results}

\section{Word Reading}

Owing to the progressive nature of $\mathrm{SD}$, each observation was treated as independent for the purposes of the main cross-sectional analysis (N. Graham et al., 2000; Lambon Ralph et al., 2001). The overall accuracy of reading performance, averaged across patients to obtain 12 levels of semantic knowledge, as defined by the average of each patient's picture naming and WPM matching scores, is presented in Figure 5B in order to illustrate the overall pattern of performance across the four different conditions.

Overall accuracy. The individual observations from all patients are presented in Figure 6B for each condition as a function of their composite semantic score. These data were analyzed using a repeated measures ANOVA in which frequency and regularity were entered as within-subject factors and composite semantic score was included as an independent linear predictor. The results showed strong effects of frequency, $F(1,98)=178.61, p<.0005$, and regularity, $F(1,98)=156.21, p<.0005$, and a pronounced Frequency $\times$ Regularity interaction, $F(1,98)=27.24, p<.0005$, reflecting the larger impact of frequency on exception than on regular words and the larger impact of regularity on low- than on high-frequency words. This pattern of interaction was equally apparent across all levels of semantic knowledge, $F(1,98)<1$. When considered as a group, in other words, the SD patients had a surface dyslexic profile.

Level of semantic knowledge significantly predicted accuracy of reading overall, $F(1,98)=83.43, p<.0005$. The degree of correspondence between semantic knowledge and reading performance is reflected in the slope of the regression lines provided for each stimulus condition in Figure 6B: for HR, $B=0.19, t(98)=$ $5.85, p<.0005$; for LR, $B=0.39, t(98)=5.83, p<.0005$; for HE, $B=0.45, t(98)=8.34, p<.0005$; for LE, $B=0.61, t(98)=$ 9.87, $p<.0005$. As is apparent in the slopes of these regression lines, the relationship between semantic knowledge and reading performance was stronger for low- than for high-frequency words, $F(1,98)=20.79, p<.0005$, and stronger for exception than for regular words, $F(1,98)=32.02, p<.0005$.

Outliers, defined as observations with standardized residuals of \pm 2 , are indicated for each condition separately in Figure $6 \mathrm{~B}$ by asterisks. Accuracy of reading performance fell below that predicted according to composite semantic score for five observations among high-frequency regular words (A.T.6, F.M.8, I.F.3, M.G.3, and P.Su.1), five observations among low-frequency regular words (E.K.2, I.F.3, M.G.3, N.S.2, and P.Su.1), six observations among high-frequency exception words (D.H.2, F.M.8, I.F.3, J.H.1, J.G.3, and M.G.3), and three observations among low-frequency exception words (N.S.1, N.S.2, and J.P.4). Accuracy of reading performance fell above that predicted according to semantic score for one observation among the high-frequency exception words (V.H.9) and for two observations among the low-frequency exception words (E.B.1 and M.G.1). This number of outliers approximates the 5\% that would be expected if the observations were randomly drawn from a population with a normal distribution of reading accuracy, which would seem to validate our weighting of the different versions of the network in the preceding analysis of the simulation data.

LARC errors. For each observation of reading data, the proportion of responses constituting LARC errors was computed according to the same criteria used to classify the errors of the triangle model after lesioning, as provided in Appendix A. The percentages of LARC errors produced by the patients are displayed in Figure 7B for each condition as a function of composite semantic score. These data were analyzed using a repeated measures ANOVA in which frequency and regularity were entered as within-subject factors and composite semantic score was included as an independent linear predictor. The results showed strong effects of frequency, $F(1,98)=44.03, p<.0005$, and regularity, $F(1,98)=161.19, p<.0005$, and a Frequency $\times$ Regularity interaction, $F(1,98)=39.08, p<.0005$, reflecting the larger impact of frequency on exception than on regular words and the larger impact of regularity on low- than on high-frequency words. This pattern of interaction was equally apparent across all levels of semantic knowledge, $F(1,98)<1$. Hence the pattern of LARC errors produced by the patients conformed to the pattern typical of surface dyslexia.

Level of semantic knowledge significantly predicted occurrence of LARC errors for all conditions, $F(1,98)=39.06, p<.0005$. The degree of correspondence between semantic knowledge and occurrence of LARC errors is reflected in the slope of the regression lines provided for each stimulus condition in Figure 7B: for $\mathrm{HR}, B=-0.03, t(98)=-3.83, p<.0005$; for LR, $B=-0.02$, $t(98)=-2.55, p=.012$; for HE, $B=-0.21, t(98)=-6.14, p<$ .0005 ; for LE, $B=-0.19, t(98)=-4.33, p<.0005$. As is apparent in the slopes of these regression lines, the relationship between semantic knowledge and occurrence of LARC errors was stronger for exception than for regular words, $F(1,98)=30.79, p<.0005$, but in contrast to the analysis of overall accuracy, the strength of the relationship did not vary according to frequency, $F(1,98)<1$.

\section{Nonword Reading}

As is apparent in Table 1, average nonword reading performance in this group was somewhat impaired, with a mean accuracy of $78.53 \%(S D=22.51)$. In contrast to all word conditions, 
however, nonword reading performance was not significantly predicted by level of semantic knowledge $(B=0.15), t(33)<1$, which accounted for only $2.5 \%$ of the available variance.

\section{Quantifying Prediction Accuracy}

Thus far, we have observed an extremely good qualitative fit between parallel analyses of the simulation and patient data. Assessing the fit in a more quantitative fashion was a challenge, as the individual observations from the simulation and the patients are not directly comparable: The former consisted of 108 observations derived from a normal weighting of five versions of the network sampled equally across 12 specific levels of lesion severity, whereas the latter consisted of 100 observations derived from 51 individuals sampled variably across all levels of semantic impairment. It was, however, possible to assess the fit between the two by using the averaged model data presented in Figure 5A to predict the averaged patient data presented in Figure 5B. Linear regressions using these showed a highly significant relationship between the model and patient data for all conditions, with more than $90 \%$ of the available variance in the patients' performance accurately predicted by the values derived from the simulation: for $\mathrm{HR}, B=1.36, t(11)=-10.96, p<.0005, R^{2}=.92$; for LR, $B=$ $1.03, t(11)=9.16, p<.0005, R^{2}=.90$; for HE, $B=0.98, t(11)=$ $13.65, p<.0005, R^{2}=.95$; for LE, $B=0.87, t(11)=11.21, p<$ $.0005, R^{2}=.93$.

\section{Classical Single Dissociations}

As discussed in the introduction, some discrepancies between level of semantic knowledge and accuracy of exception word reading are predicted within both dual-route and triangle model accounts of surface dyslexia. Within the dual-route model, these classical single dissociations establish the functional independence of lexical and semantic knowledge, irrespective of their actual frequency of occurrence. In contrast, within the triangle model, these discrepancies reflect premorbid individual differences in degree of semantic reliance during reading aloud, and on the assumption that this variation follows a normal distribution in the population, they should occur infrequently relative to cases of association. For this reason, it is of interest to establish how many of the 100 observations in the present sample may be considered to represent a classical single dissociation between level of semantic knowledge and accuracy of exception word reading.

Low-frequency exception word reading and semantic status for the full group are displayed in Figure 8A. Performance that is two standard deviations below normal on the semantic measures is indicated by the vertical line, and performance that is two standard deviations below normal on the reading task is indicated by the horizontal line. As already demonstrated, the vast majority of observations fall into the impaired range on both measures. Two observations fall into the range of normal performance on both the semantic and the reading measures (B.C.1 and G.C.1); these are straightforward cases in which a semantic deficit was detected at a very early stage and, though observable on more difficult semantic tests, was not yet apparent either on our relatively easy tests of naming and word-picture matching or through any impact on reading. In the upper right quadrant of the graph that represents normal low-frequency exception word reading in the presence of a clear semantic impairment, there are three cases (M.A.1, E.B.1, and M.G.1) that would qualify as a classical single dissociation of this type, with the observation deriving from the first testing round for each patient. It is worth noting that, in fact, only two of these observations were outliers in terms of level of reading performance for degree of semantic impairment as predicted by the line of best fit for all observations. The bottom left quadrant of the graph that represents a significant impairment in low-frequency exception
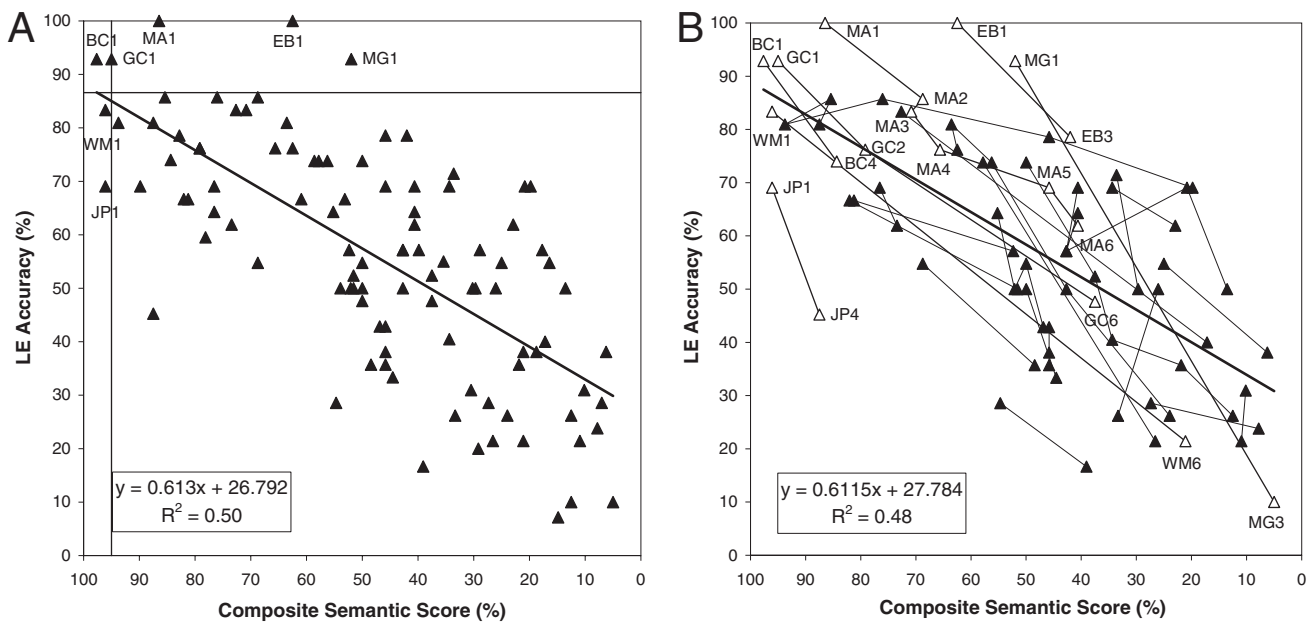

Figure 8. (A) Overall accuracy results for 100 observations of reading performance from 51 semantic dementia patients for low-frequency exception (LE) words according to level of semantic knowledge. The horizontal line represents two standard deviations below control performance on LE words; the vertical line represents two standard deviations below control performance on the composite semantic score. (B) Overall accuracy results for 75 observations of reading performance from 27 semantic dementia patients for low-frequency exception words according to level of semantic knowledge. Repeated observations for each patient are connected by lines to indicate progression over time. Unfilled symbols highlight cases of particular interest. 
word reading in the presence of relatively unimpaired semantic knowledge contains only two observations (W.M.1 and J.P.1), again deriving from the first testing round for both patients. Neither of these observations was an outlier in terms of level of reading performance for degree of semantic impairment as predicted by the line of best fit for all observations. It should be stressed that both W.M. and J.P. at their first testing round (like B.C. and G.C. mentioned above) already had a semantic impairment, measurable on more difficult tasks such as the Graded Naming Test (McKenna \& Warrington, 1983). The fact that the initial observations for these patients fell within the control range on the semantic measures used in this study underlines the importance of considering relative task difficulty when defining classical single dissociations (Shallice, 1988).

\section{Progression Over Time}

Although both dual-route and triangle model accounts of surface dyslexia predict the occurrence of discrepancies between level of semantic knowledge and accuracy of exception word reading, the triangle model's account of these cases in terms of individual difference in premorbid semantic reliance leads to the further prediction that in the case of a neurodegenerative condition such as $\mathrm{SD}$, these dissociations should be temporary. How does this prediction fare with respect to the present data set? Fortunately, we had longitudinal data for each of the cases of discrepancy, depicted in Figure 8B, which illustrates progression over time of the 27 patients who contributed two or more observations. The regression line fitted to these 76 observations is significant $(B=0.611)$, $t(75)=8.19, p<.0005$, and accounts for $48 \%$ of the available variance, a very similar result to that obtained in our previous consideration of the full set of 100 observations. Data points deriving from a single patient are joined by lines in Figure 8B, and it is immediately apparent that the SD-squared pattern holds longitudinally as well as cross-sectionally.

As can be seen in Figure 8B, the two individuals (G.C. and B.C.) who were initially within the normal range on both reading and semantic tests showed the typical decline on both measures over time. The three patients with initially intact reading of lowfrequency exception words despite an appreciable semantic deficit all became surface dyslexic as their semantic deficits increased in severity. The progression in M.A. and E.B., whose successive testing rounds were no more than a year apart, requires little comment. For M.G., on the other hand, we should note that a much longer delay intervened between the two reading assessments displayed in Figure 8B, because this patient moved away from the southeast of England, making follow-up difficult. By the time that we were able to see her again, she was almost at floor on both reading and semantic measures. Finally, what about W.M. and J.P., the cases in which low-frequency exception word reading was initially impaired despite a relatively mild level of semantic impairment? In keeping with their somewhat disproportionate reading impairment on first testing, by the next time that reading was assessed, a deterioration in semantic scores had emerged with a further decline in exception word reading accuracy.

\section{Summary}

Reading aloud by this group of SD patients revealed strong effects of frequency and regularity and an interaction between them characteristic of surface dyslexia. The magnitude of the interaction between frequency and regularity remained constant across all levels of semantic knowledge. Accuracy of reading aloud was significantly related to level of semantic knowledge for all word types, but the strength of this relationship was significantly stronger for low- than for high-frequency words and for exception than for regular words. LARC errors increased with decreasing semantic knowledge and were most common to exception words, irrespective of frequency. Although nonword reading by these patients was mildly impaired, it was not significantly related to level of semantic knowledge. Hence the pattern of reading observed in this large group of SD patients, and its relationship to level of semantic knowledge, confirmed all of the predictions derived from the new triangle model simulation presented earlier. Indeed, the average reading scores from the simulation accounted for a striking amount of the variance in the average reading scores of the patients for every condition.

Amid the overwhelming SD-squared pattern in this patient group were a small number of instances of discrepancy between level of semantic knowledge and accuracy of low-frequency exception word reading. In three cases, low-frequency exception word reading performance was within the normal range despite an appreciable semantic impairment, a rate that closely mirrors the incidence of such cases previously reported in the literature. Within the triangle model account, such cases reflect natural variation in the degree of premorbid reliance on semantic activation of phonology for correct reading of low-frequency exception words. According to this account, in a neurodegenerative condition such as SD, any cases of intact low-frequency exception word reading should be temporary, such that a surface dyslexic reading pattern should emerge in these individuals as the semantic impairment inevitably worsens over time. The longitudinal pattern of performance of these cases in the present sample provided uniform confirmation of this prediction.

\section{GENERAL DISCUSSION}

In the present article, we set out to test predictions derived from the triangle model account of surface dyslexia, distinguished by its assumption of a causal link between the integrity of semantic knowledge and accurate reading of low-frequency exception words (Plaut et al., 1996). Within the triangle model, accurate pronunciation of exception words comes to depend on semantic activation of phonology as a consequence of the division of labor that develops in normal reading over the course of training, which functions to optimize the efficiency of the reading system as a whole. The triangle model account therefore predicts that there should be (a) a strong association between degraded semantic knowledge and impaired reading of low-frequency exception words and (b) a significant relationship between the degree of semantic degradation and the severity of the surface dyslexia observed.

Moreover, because the direct $\mathrm{O} \rightarrow \mathrm{P}$ connections of the triangle model can learn to pronounce exception words correctly, this account allows for the possibility that normal readers will vary somewhat in the degree to which they rely on $\mathrm{S} \rightarrow \mathrm{P}$ activation to support correct exception word reading (Plaut, 1997). Hence, the triangle model is also differentiated by the idea that there may be individual differences in the extent of semantic damage required to 
produce a surface dyslexic reading pattern. This aspect of the triangle model results in the additional predictions that (c) occasional discrepancies between level of semantic knowledge and accuracy of exception word reading would be expected as a result of these premorbid individual differences and (d) such discrepancies will be temporary in the case of a neurodegenerative condition like SD, with a surface dyslexic reading pattern emerging as semantic memory inevitably deteriorates over time.

\section{A Connectionist Explanation}

To quantify the triangle model's predictions concerning the reading performance expected in $\mathrm{SD}$, we provided a simulation using the Plaut et al. (1996) network, which we modified in two ways. First, we incorporated variation in terms of premorbid semantic reliance through training five instantiations of the network that differed only in terms of the strength of the frequency weighted " $\mathrm{S}$ " $\rightarrow \mathrm{P}$ activation supplied during training, following the method used by Plaut (1997). Second, each version of the network was then lesioned not only by a gradual reduction in the strength of " $\mathrm{S}$ " $\rightarrow \mathrm{P}$ activation, as in the original Plaut et al. (1996) simulations, but also through the addition of inverse frequencyweighted Gaussian noise to the " $\mathrm{S}$ " $\rightarrow \mathrm{P}$ activation throughout the course of its reduction. The noise was intended to reflect the claim, consistent with SD patients' errors in picture naming, that the $\mathrm{S} \rightarrow \mathrm{P}$ activation for these patients is not only diminished but also less accurate.

The results of this new simulation revealed a significant relationship between accuracy of reading aloud performance and lesion severity for all word classes, but the strength of this relationship was graded according to both frequency and regularity, such that it was strongest for low-frequency exception words across all levels of lesion severity. The same pattern was obtained with reference to regularity (but not frequency) when only the LARC errors of the model were considered. This finding indicates that the decrement in performance for low-frequency regular words with increasing lesion severity was associated with error responses other than LARCs, in accordance with our proposal that a more noisy $\mathrm{O} \rightarrow \mathrm{P}$ computation emerges as a result of increasingly less specific or incorrect $\mathrm{S} \rightarrow \mathrm{P}$ activation as meaning-level knowledge degrades.

Having established the specific predictions of the triangle model with regard to reading aloud in $\mathrm{SD}$, we then evaluated these with reference to 100 observations of reading performance, on exactly the same items, drawn from 51 patients with this disorder. There was a striking concordance between the results of the simulation and the reading performance of the patients. Specifically, the patients' reading accuracy showed a significant relationship to the level of semantic deficit for all word classes, but as in the model, the strength of this relationship was graded according to both frequency and regularity. Moreover, LARC errors in the patient data closely mirrored the results obtained in the simulation, with effects of regularity but not frequency. As in the model, this outcome supports the present hypothesis concerning the impact on reading aloud of decreased specificity or accuracy of semantic activation of phonology.

Although surface dyslexic failures to read aloud a word correctly are most common for low-frequency exception words, the increasing deficit for high-frequency exception words seen in the current simulation and patient data is not unexpected. In the original division-of-labor simulations (Plaut et al., 1996), success on high-frequency exceptions declined with increasing lesion severity, and the same pattern has been observed in SD patients (McCarthy \& Warrington, 1986; Patterson \& Hodges, 1992; Patterson et al., 2006). The emerging deficit for low-frequency regular words observed in the simulation and patient data presented here, however, warrants further comment. This outcome in the network diverges from the results of the lesion simulation of Plaut et al. (1996) and is caused by the addition of noise to the " $\mathrm{S}$ " $\rightarrow \mathrm{P}$ activation. The vital point is that the patient data revealed a similar decline in accuracy of low-frequency regular word reading with decreasing levels of semantic knowledge. This phenomenon has, in fact, been noted in the reading performance of a number of SD cases, mainly for accuracy (e.g., Funnell, 1996; K. S. Graham et al., 1994; Noble et al., 2000; Patterson et al., 1996) and occasionally for latency (Gold et al., 2005), an issue to which we shall return in due course. The current investigation has provided a working hypothesis concerning the basis for the phenomenon, namely, the impact of incorrect activation of phonology by semantics.

Increasingly less specific or incorrect semantic activation of phonology in SD was proposed in a previous connectionist model of meaning-level representation (Rogers, Lambon Ralph, Garrard, et al., 2004). As this model did not, however, incorporate orthographic representations, it could not be used in the present study. We acknowledge that a clear limitation of the present simulations is the use of " $\mathrm{S}$ " $\rightarrow \mathrm{P}$ activation to approximate a semantic contribution to phonology, which in turn necessitated the introduction of noise to approximate the consequences of semantic degradation. We chose this method as it rendered the investigation of the impact of premorbid individual differences computationally feasible. A further simulation within an implementation of the triangle model that incorporates realistic semantic representations, such as that of Harm and Seidenberg (2004), will be important to validate our working hypothesis concerning the consequences of semantic damage on $\mathrm{O} \rightarrow \mathrm{P}$ computation.

Given the significant relationship between level of semantic deficit and reading accuracy for all word classes in both the model and the patients, might it be argued that degradation of meaninglevel knowledge merely impairs performance overall, with the severity of impairment corresponding to the difficulty of each word class? We think not. Reading aloud of nonwords would seem to be at least as difficult as reading aloud of low-frequency regular words, if not more so by virtue of their novelty (Binder, Medler, Desai, Conant, \& Liebenthal, 2005; Fiez, Balota, Raichle, \& Petersen, 1999; Forster \& Chambers, 1973; Glushko, 1979; McCann \& Besner, 1987; Monsell, Patterson, Graham, Hughes, \& Milroy, 1992). In contrast to all four real word classes, however, accuracy of nonword reading by (a subset of) the SD patients did not decline significantly as semantic knowledge deteriorated. Hence we would argue that the pattern of data observed here cannot be attributed merely to differential difficulty among stimulus types.

Nonetheless, as has been observed in some previous studies of nonword reading in SD (N. Graham et al., 2000), overall performance was somewhat below normal, and the basis for this phenomenon remains to be established. The assumption in the present simulations (and previous simulations; Plaut et al., 1996) that 
phonology does not receive any semantic activation during the processing of novel letter strings is clearly an oversimplification, as nonwords activate the semantic representations of orthographically similar words to at least some extent (Forster \& Hector, 2002), albeit much less than for words (Plaut, 1997). In a fuller implementation of the triangle model, such as that of Harm and Seidenberg (2004), O $\rightarrow$ S connections would allow such partial semantic activation to occur for nonwords, which we suggest should introduce some degree of constant noise into the computation of the pronunciation of novel letter strings in SD.

This largest ever case-series consideration of reading aloud performance in SD has provided resounding support for the predictions derived from the triangle model's account of surface dyslexia. There was an extensive association between degraded semantic knowledge and impaired reading of low-frequency exception words, with a highly significant relationship between the degree of semantic degradation and the severity of the surface dyslexia observed. Indeed, the averaged simulation data predicted over $90 \%$ of the available variance in the averaged patient data for all conditions, a fit that can be considered nothing less than remarkable.

What of the additional predictions that occasional discrepancies between level of semantic knowledge and accuracy of exception word reading would be expected owing to premorbid individual differences in semantic reliance during reading aloud, and that such dissociations should be longitudinally temporary? In the present data set, 3 of the 51 cases showed normal exception word reading accuracy despite a significant semantic impairment when first tested. All three progressed into a surface dyslexic reading pattern with further semantic deterioration. Within the triangle model framework, these three cases represent a manifestation of an unusually strong reliance on $\mathrm{O} \rightarrow \mathrm{P}$ computation for accurate exception word reading prior to disease onset. As these individuals did not rely on $\mathrm{S} \rightarrow \mathrm{P}$ activation as extensively as most during reading aloud, exception word reading did not begin to suffer until a greater decline in semantic knowledge had occurred. Once it did so, however, reading performance followed the trajectory of decline characteristic of the full group. The results therefore demonstrate that what varies between different individuals is not whether a semantic deficit will impair exception word reading but rather when (i.e., at what level of severity) it will do so.

Although it is computationally possible that some individuals may possess a premorbid division of labor so extreme as to leave low-frequency exception word reading unaffected even under conditions of severe semantic damage, we would argue that such a scenario is highly unlikely in terms of optimizing the capacity of the reading system as a whole. The underlying principle of the division-of-labor hypothesis is that, assuming the development of connections between semantics and phonology prior to reading, a degree of reliance on semantic activation for correct reading of words that are exceptional and/or low-frequency increases the efficiency of the direct pathway in that it may devote its resources to mapping the most typical and common correspondences between spelling and sound. Hence, although there may be variations in the balance between $\mathrm{O} \rightarrow \mathrm{P}$ and $\mathrm{S} \rightarrow \mathrm{P}$ influences on reading, it seems unlikely that any reader would rely entirely on one or the other. We acknowledge that this hypothesis regarding individual differences in division of labor is difficult to test in the absence of premorbid estimates of semantic reliance during reading aloud. Some evidence of differential semantic reliance among normal readers already exists, however-not only in behavior (Strain \& Herdman, 1999) but also in neural activation (Price et al., 2003).

The triangle model interpretation of the case-series data presented here has the advantage of explaining the full spectrum of observed performance: from the occasional observation of initially intact exception word reading in the presence of a moderate semantic deficit, via the typical combination of semantic impairment and surface dyslexia, through to the rare observation of impaired exception word reading under conditions of only a mild semantic deficit. In this way, the triangle model is able to provide a principled account of not only the central tendency of reading performance observed in this large group of SD patients but also the distribution in degree of reading impairment, via quantitative variation in a single variable-namely, division of labor between the direct and semantic pathways from orthography to phonology. Of course, the present account does not speak to the origins of such premorbid individual differences in reading style, but simulations within developmentally plausible instantiations of the triangle model (Harm \& Seidenberg, 2004) should generate alternative hypotheses concerning this issue that may be explored in future behavioral and neuroimaging studies of normal readers.

To summarize, the patient data presented here demonstrate an overwhelming association between degraded semantic knowledge and surface dyslexia, with half of the available variance in lowfrequency exception word reading accounted for by a simple composite semantic score from tests involving no reading whatsoever. A principled account of this association is provided by the connectionist triangle model of reading aloud owing to its assumption of a causal relationship between semantic activation of phonology and successful exception word reading. This link between knowledge of word meaning and reading aloud is explicitly rejected in the dual-route model of Coltheart et al. (Coltheart, 2006; Coltheart, Langdon, \& Haller, 1996; Coltheart et al., 2001). We therefore now turn our attention to how such a framework might attempt to account for the current findings.

\section{An Alternative Interpretation?}

As mentioned earlier, reading aloud proceeds within the DRC model by the parallel operation of both the nonlexical and lexical routes, with activation pooled at the phoneme level. The nonlexical route applies strict grapheme-phoneme rules, allowing correct pronunciation of regular words and nonwords. The lexical route consists of two pathways: direct and semantic. The implemented direct lexical route translates all known words by means of oneto-one correspondences between whole-word orthographic and phonological lexical representations, allowing pronunciation of exception and regular words. Although the framework includes an unimplemented lexical semantic pathway that may also correctly translate real words, this pathway is not considered to be involved in the normal course of translation from print to sound. The model therefore cannot simulate the influence of a semantic variable, imageability, on naming latencies for low-frequency exception words in normal readers (Cortese et al., 1997; Shibahara et al., 2003; Strain \& Herdman, 1999; Strain et al., 1995, 2002).

Given the strict separation between lexical and semantic knowledge that characterizes the DRC model, accounting for the rare cases of classical single dissociation observed in the present study is a trivial exercise within this framework. Specifically, preserved low- 
frequency exception word reading in the face of an appreciable semantic impairment merely reflects damage to the semantic system in the presence of an intact direct lexical route. The converse pattern of impaired low-frequency exception word reading combined with only a slight semantic impairment simply indicates mild damage to the semantic system combined with more substantial damage to one of the components of the direct lexical route. To date, the only simulation of surface dyslexia within the implemented form of the DRC model used partial damage to the orthographic input lexicon to produce the frequency graded impairments seen in most cases of surface dyslexia (Coltheart et al., 1996).

In keeping with traditional neuropsychological logic, a single case of each type of dissociation between level of semantic knowledge and accuracy of low-frequency exception word reading, when considered jointly, provide the double dissociation that establishes the functional independence of lexical and semantic representations (Coltheart, 2006; Noble et al., 2000; Shallice, 1988). Yet is there any independent evidence to support this categorical distinction between lexicon and semantics? Although Coltheart (2004) argued that SD patients with intact lexical decision accuracy constitute just such evidence, there have been few convincing demonstrations of such a pattern in the literature to date. Several studies have demonstrated that intact lexical decision performance is seen in SD only when the nonword foils can be distinguished from word targets on the basis of orthographic or phonological characteristics, with impaired performance emerging when targets and foils are matched on these variables (Diesfeldt, 1992; Rogers, Lambon Ralph, Hodges, \& Patterson, 2004), as would be expected according to a connectionist account (Plaut, 1997).

There has, however, been a recent report of intact lexical decision performance in the SD patient E.M. using pseudohomophonic foils that did not differ from the word targets in terms of average positional bigram frequencies (Blazely et al., 2005). It is worth noting that in spite of this matching, a number of these foils contained illegal bigrams and/or nonexistent bodies (e.g., forkk, trree, shooe), which may have allowed at least some decisions to be made on the basis of orthographic form. ${ }^{4}$ Nonetheless, such highly accurate lexical decision performance in a patient with a marked semantic impairment does require attention and explanation. In this respect it is worth noting that E.M. was also an unusual case by virtue of her perfect exception word reading performance. At present, then, it appears that the functional independence of lexical and semantic knowledge so central to the DRC model rests entirely on this one observation of intact lexical decision performance in a single SD patient.

In fact, the architectural separation of lexical and semantic knowledge within the DRC model renders its account of the overwhelming SD-squared pattern distinctly unparsimonious. Although this association constitutes the vast majority of evidence concerning reading aloud performance in SD, multiple sites of impairment within the DRC model are required to explain it. That is, the DRC (or indeed any) model must assume damage to (a) the semantic system in SD to explain impaired performance across all tests tapping meaning-level knowledge; but because of the lexical pathway of the DRC framework, this central semantic impairment will not result in surface dyslexia. Therefore, the SD-squared results must be explained by additional damage to either (b) the orthographic input lexicon, (c) the phonological output lexicon, (d) the direct lexical connections between these lexicons, or (e) some combination of these three (Blazely et al., 2005).

Moreover, as the nonlexical route of the DRC model is functionally independent of the lexical route, the model presumably predicts intact regular word reading in SD and thus has no explanation for the significant relationship between level of semantic knowledge and accuracy of both high- and particularly low-frequency regular word reading observed here. Given that Cumming et al. (2006) have recently reported SD patients' letter identification to be intact, albeit slightly slowed, it does not seem likely that errors to regular words resulted from difficulty in identifying their component letters. We can only presume that the DRC model would have to propose yet another impairment to (f) one or more of the components of the nonlexical route. Explaining the current data via deficits within all three DRC pathways between orthography and phonology seems unparsimonious in the extreme.

Given that the DRC model must postulate additional damage to the lexical reading route in order to account for the SD-squared pattern observed here, a key issue that arises is why these lexical processing deficits should be so prevalent among SD patients. This has been attributed to the spread of atrophy, over the course of disease progression, from the left anterior inferior temporal areas necessary for semantic processing to any one of a number of additional temporal and occipital regions that may be involved in lexical processing (Blazely et al., 2005; Noble et al., 2000). By this account, the prevalence of surface dyslexia in SD is dismissed as merely an accident of the anatomical contiguity of the functionally separate brain regions responsible for semantic and lexical processing. A critical question here is of course whether any neuroanatomical evidence actually exists to corroborate this proposal.

One basis for the anatomical contiguity hypothesis derives from the observation by Noble et al. (2000) of the emergence of an explicit letter-by-letter reading strategy in one of their three surface dyslexic SD patients (T.M.). This was taken to indicate the spread of atrophy to left inferior temporo-occipital regions and left mesial occipital cortex. Although it is true that lesions to these areas produce pure alexia, a condition defined by an enhanced effect of word length and often accompanied by an explicit letterby-letter reading strategy (Friedman, Ween, \& Albert, 1993; McCarthy \& Warrington, 1990), no neuroradiological evidence was provided to demonstrate that these areas were compromised in T.M. The crucial implication of Noble et al.'s observation is that the hypothesized damage to left temporo-occipital regions in T.M. was the culmination of a gradual posterior and superior spread of atrophy from the left temporal pole and, hence, that the surface dyslexia observed before the letter-by-letter reading strategy emerged was produced by damage to areas involved in lexical processing.

Yet a number of studies to date have demonstrated that even in the later stages of SD, atrophy and hypometabolism remain centered primarily on the anterior temporal lobes (Boxer et al., 2003; Mummery et al., 2000; Nestor et al., 2006). We are not denying that in some cases atrophy does spread both superiorly and posteriorly to encompass other language processing areas, as proposed by Noble et al. (2000). Critically, however, neither the presence

\footnotetext{
${ }^{4}$ We are grateful to Max Coltheart for providing us with the stimuli used in this task.
} 
nor the direction of such spreading is universal in SD, whereas the case-series data presented in this article demonstrate that the prevalence of surface dyslexia ultimately is. Hence it does not seem likely that the anatomical contiguity hypothesis can account for these results. What would be required to support this explanation would be a case-series investigation of reading in SD with structural and functional imaging data indicating that surface dyslexia is not seen in SD patients with damage confined to the anterior temporal lobes, but is observed only among patients with deterioration of more superior and/or posterior regions.

In fact, existing structural imaging data appear to disconfirm the predictions of the anatomical contiguity hypothesis. Recently, Gold et al. (2005) observed the enhanced length effect that defines pure alexia in the regular word reading latencies of six mild cases of SD. These data have been taken as evidence for increased reliance on the nonlexical pathway within the DRC account, as this procedure incorporates a serial component. Increased nonlexical reliance must presumably result from damage to areas responsible for lexical processing over and above those responsible for semantic processing. In contrast, following Cumming et al. (2006), we attribute the significant effect of word length on reading latencies observed in SD to reduced top-down semantic support of orthographic processing. This latter explanation is consistent with Gold et al.'s finding that significant cortical thinning in their group of SD patients was limited to the left temporal pole, with a smaller area also apparent in the right temporal pole. Moreover, five of the six mild SD patients considered in that study were already surface dyslexic, in direct contradiction to what would be expected according to the anatomical contiguity hypothesis among those with damage confined to the anterior temporal lobes.

The anatomical contiguity hypothesis has also recently been questioned on the basis of behavioral data by Patterson et al. (2006), who studied 14 SD patients and demonstrated that performance on low-frequency atypical items was compromised in every single case, not only for reading but also for the tasks of spelling, past-tense inflection, lexical decision, object decision, and delayed copy drawing. Across the whole group, the extent of the impairment on these atypical items in both verbal and nonverbal receptive and productive tasks corresponded closely to the degree of the patients' semantic deficit. Given the varied nature of the six tasks, the anatomical contiguity account would have to propose damage to multiple regions of additional processing, and it seems highly implausible that this could be uniformly true for all 14 patients.

In this section, we have argued against the DRC model's possible account of the SD-squared pattern on a number of grounds. First, there appears to be little independent evidence for the strict separation between lexical and semantic knowledge that defines the DRC model and allows it to explain rare cases of dissociation. Second, an unparsimonious explanation based on unconfirmed speculation concerning the spread of atrophy in SD is required to explain the vast majority of the evidence presented in this case series. Coltheart et al. (2001) expressly disavowed assessment of theoretical adequacy of a given cognitive model on the basis of parsimony (cf. Jacobs \& Grainger, 1994), instead favoring a criterion of predictive accuracy. We would argue that in light of the SD reading data that we have presented in this article, the triangle model offers both the most parsimonious and the most predictively accurate account of the ubiquitous association between SD and surface dyslexia.

\section{CONCLUSION}

The 100 observations of reading data from 51 SD patients presented here confirm the predictions of the triangle model concerning the consequences of deterioration of meaning-level knowledge for reading aloud. Owing to a graded division of labor that develops throughout the course of training within this model of the reading system, semantic activation comes to support the pronunciation of words that are low in frequency or atypical in terms of their spellingsound correspondences. Hence disruption to semantic activation of phonology, as occurs in SD, results in surface dyslexia. Moreover, connectionist accounts that invoke differential semantic reliance according to both the frequency and the typicality of the stimulus apply well beyond reading aloud, successfully predicting performance of SD patients in a number of other linguistic and nonlinguistic tasks. Connectionist models therefore offer an elegant explanation of the SD-squared phenomenon that is derived from general principles applicable across a number of disparate cognitive domains.

\section{References}

Behrmann, M., \& Bub, D. (1992). Surface dyslexia and dysgraphia: Dual routes, a single lexicon. Cognitive Neuropsychology, 9, 209-258.

Binder, J. R., Medler, D. A., Desai, R., Conant, L. L., \& Liebenthal, E. (2005). Some neurophysiological constraints on models of word naming. NeuroImage, 27, 677-693.

Blazely, A. M., Coltheart, M., \& Casey, B. J. (2005). Semantic impairment with and without surface dyslexia: Implications for models of reading. Cognitive Neuropsychology, 22, 695-717.

Boxer, A. L., Rankin, K. P., Miller, B. L., Schuff, N., Weiner, M., Gorno-Tempini, M.-L., \& Rosen, H. J. (2003). Cinguloparietal atrophy distinguishes Alzheimer disease from semantic dementia. Archives of Neurology, 60, 949-956.

Bozeat, S., Lambon Ralph, M. A., Graham, K. S., Patterson, K., Wilkin, H., Rowland, J., et al. (2003). A duck with four legs: Investigating the structure of conceptual knowledge using picture drawing in semantic dementia. Cognitive Neuropsychology, 20, 27-47.

Bozeat, S., Lambon Ralph, M. A., Patterson, K., Garrard, P., \& Hodges, J. R. (2000). Non-verbal semantic impairment in semantic dementia. Neuropsychologia, 38, 1207-1215.

Bozeat, S., Lambon Ralph, M. A., Patterson, K., \& Hodges, J. R. (2002). When objects lose their meaning: What happens to their use? Cognitive, Affective and Behavioral Neuroscience, 2, 236-251.

Bub, D., Cancelliere, A., \& Kertesz, A. (1985). Whole-word and analytic translation of spelling to sound in a non-semantic reader. In K. Patterson, M. Coltheart, \& J. C. Marshall (Eds.), Surface dyslexia: Neuropsychological and cognitive studies of phonological reading (pp. 3-34). London: Erlbaum.

Caramazza, A., \& McCloskey, M. (1988). The case for single-patient studies. Cognitive Neuropsychology, 5, 517-528.

Cipolotti, L., \& Warrington, E. K. (1995). Semantic memory and reading abilities: A case report. Journal of the International Neuropsychological Society, 1, 104-110.

Coltheart, M. (2001). Assumptions and methods in cognitive neuropsychology. In B. Rapp (Ed.), The handbook of cognitive neuropsychology: What deficits reveal about the human mind (pp. 3-21). New York: Psychology Press.

Coltheart, M. (2004). Are there lexicons? Quarterly Journal of Experimental Psychology: Human Experimental Psychology, 57(A), 1153-1171.

Coltheart, M. (2006). Acquired dyslexias and the computational modelling of reading. Cognitive Neuropsychology, 23, 96-109.

Coltheart, M., Langdon, R., \& Haller, M. (1996). Computational cognitive neuropsychology and acquired dyslexia. In B. Dodd, L. Worrall, \& R. 
Campbell (Eds.), Evaluating theories of language: Evidence from disordered communication (pp. 9-37). London: Whurr.

Coltheart, M., Rastle, K., Perry, C., Langdon, R., \& Ziegler, J. (2001). DRC: A dual route cascaded model of visual word recognition and reading aloud. Psychological Review, 108, 204-256.

Cortese, M. J., Simpson, G. B., \& Woolsey, S. (1997). Effects of association and imageability on phonological mapping. Psychonomic Bulletin \& Review, 4, 226-231.

Cumming, T. B., Patterson, K., Verfaellie, M., \& Graham, K. S. (2006). One bird with two stones: Abnormal word length effects in pure alexia and semantic dementia. Cognitive Neuropsychology, 23, 130-161.

Diesfeldt, H. F. A. (1992). Impaired and preserved semantic memory functions in dementia. In L. Backman (Ed.), Memory functioning in dementia (pp. 227-263). Amsterdam: Elsevier.

Ellis, A. W., \& Young, A. W. (1988). Human cognitive neuropsychology. Hove, England: Erlbaum.

Fiez, J. A., Balota, D. A., Raichle, M. E., \& Petersen, S. E. (1999). The effects of word frequency and spelling-to-sound consistency on the functional anatomy of reading. Neuron, 24, 205-218.

Folstein, M. F., Folstein, S. E., \& McHugh, P. R. (1975). Mini-Mental State: A practical method for grading the cognitive state of patients for the clinician. Journal of Psychiatric Research, 12, 189-198.

Forster, K. I., \& Chambers, S. M. (1973). Lexical access and naming time. Journal of Verbal Learning and Verbal Behavior, 12, 627-635.

Forster, K. I., \& Hector, J. (2002). Cascaded versus noncascaded models of lexical and semantic processing: The turple effect. Memory \& Cognition, 30, 1106-1117.

Friedman, R. F., Ween, J. E., \& Albert, M. L. (1993). Alexia. In K. M. Heilman \& E. Valenstein (Eds.), Clinical neuropsychology (3rd ed., pp. 37-62). New York: Oxford University Press.

Funnell, E. (1996). Response biases in oral reading: An account of the co-occurrence of surface dyslexia and semantic dementia. Quarterly Journal of Experimental Psychology: Human Experimental Psychology, 49(A), 417-446.

Gerhand, S. (2001). Routes to reading: A report of a non-semantic reader with equivalent performance on regular and exception words. Neuropsychologia, 39, 1473-1484.

Glushko, R. J. (1979). The organization and activation of orthographic knowledge in reading aloud. Journal of Experimental Psychology: Human Perception and Performance, 5, 674-691.

Gold, B. T., Balota, D. A., Cortese, M. J., Sergent Marshall, S. D., Snyder, A. Z., Salat, D. H., et al. (2005). Differing neuropsychological and neuroanatomical correlates of abnormal reading in early-stage semantic dementia and dementia of the Alzheimer type. Neuropsychologia, 43, 833-846.

Graham, K. S., Hodges, J. R., \& Patterson, K. E. (1994). The relationship between comprehension and oral reading in progressive fluent aphasia. Neuropsychologia, 32, 299-316.

Graham, K. S., Patterson, K., Pratt, K. H., \& Hodges, J. R. (1999). Relearning and subsequent forgetting of semantic category exemplars in a case of semantic dementia. Neuropsychology, 13, 359-380.

Graham, K. S., Patterson, K., Pratt, K. H., \& Hodges, J. R. (2001). Can repeated exposure to "forgotten" vocabulary help alleviate word-finding difficulties in semantic dementia? An illustrative case study. Neuropsychological Rehabilitation, 11, 429-454.

Graham, K. S., Simons, J. S., Pratt, K. H., Patterson, K., \& Hodges, J. R. (2000). Insights from semantic dementia on the relationship between episodic and semantic memory. Neuropsychologia, 38, 313-324.

Graham, N., Patterson, K., \& Hodges, J. R. (2000). The impact of semantic memory impairment on spelling: Evidence from semantic dementia. Neuropsychologia, 38, 143-163.

Harm, M. W., \& Seidenberg, M. S. (2001). Are there orthographic impairments in phonological dyslexia? Cognitive Neuropsychology, 18, 71-92.

Harm, M. W., \& Seidenberg, M. S. (2004). Computing the meanings of words in reading: Cooperative division of labor between visual and phonological processes. Psychological Review, 111, 662-720.

Hillis, A. E., \& Caramazza, A. (1991). Mechanisms for accessing lexical representations for output: Evidence from a category-specific semantic deficit. Brain and Language, 40, 106-144.

Hillis, A. E., \& Caramazza, A. (1995). Converging evidence for the interaction of semantic and sublexical phonological information in accessing lexical representations for spoken output. Cognitive Neuropsychology, 12, 187-227.

Hodges, J. R., Graham, N., \& Patterson, K. (1995). Charting the progression in semantic dementia: Implications for the organisation of semantic memory. Memory, 3, 463-495.

Hodges, J. R., \& Patterson, K. (1996). Nonfluent progressive aphasia and semantic dementia: A comparative neuropsychological study. Journal of the International Neuropsychological Society, 2, 511-524.

Hodges, J. R., Patterson, K., Oxbury, S., \& Funnell, E. (1992). Semantic dementia: Progressive fluent aphasia with temporal lobe atrophy. Brain, 115, 1783-1806.

Hodges, J. R., Patterson, K., \& Tyler, L. K. (1994). Loss of semantic memory: Implications for the modularity of mind. Cognitive Neuropsychology, 11, 505-542.

Hodges, J. R., Salmon, D. P., \& Butters, N. (1992). Semantic memory impairment in Alzheimer's disease: Failure of access or degraded knowledge? Neuropsychologia, 30, 301-314.

Howard, D., \& Patterson, K. (1992). Pyramids and palm trees: A test of semantic access from pictures and words. Bury St. Edmunds, England: Thames Valley Test Company.

Jacobs, A. M., \& Grainger, J. (1994). Models of visual word recognition: Sampling the state of the art. Journal of Experimental Psychology: Human Perception and Performance, 20, 1311-1334.

Jefferies, E., Jones, R., Bateman, D., \& Lambon Ralph, M. A. (2004). When does word meaning affect immediate serial recall in semantic dementia? Cognitive, Affective and Behavioral Neuroscience, 4, 20-42.

Jefferies, E., Jones, R. W., Bateman, D., \& Lambon Ralph, M. A. (2005). A semantic contribution to nonword recall? Evidence for intact phonological processes in semantic dementia. Cognitive Neuropsychology, 22, 183-212.

Jefferies, E., \& Lambon Ralph, M. A. (2006). Semantic impairment in stroke aphasia versus semantic dementia: A case-series comparison. Brain, 129, 2132-2147.

Jefferies, E., Lambon Ralph, M. A., Jones, R., Bateman, D., \& Patterson, K. (2004). Surface dyslexia in semantic dementia: A comparison of the influence of consistency and regularity. Neurocase, 10, 290-299.

Knott, R., Patterson, K., \& Hodges, J. R. (2000). The role of speech production in auditory-verbal short-term memory: Evidence from progressive fluent aphasia. Neuropsychologia, 38, 125-142.

Kučera, H., \& Francis, W. N. (1967). Computational analysis of presentday American English. Providence, RI: Brown University Press.

Lambon Ralph, M. A., Ellis, A. W., \& Franklin, S. (1995). Semantic loss without surface dyslexia. Neurocase, 1, 363-369.

Lambon Ralph, M. A., Graham, K. S., Ellis, A. W., \& Hodges, J. R. (1998). Naming in semantic dementia: What matters? Neuropsychologia, 36, 775-784.

Lambon Ralph, M. A., McClelland, J. L., Patterson, K., Galton, C. J., \& Hodges, J. R. (2001). No right to speak? The relationship between object naming and semantic impairment: Neuropsychological evidence and a computational model. Journal of Cognitive Neuroscience, 13, 341-356.

Lambon Ralph, M. A., Moriarty, L., Sage, K., Ackerman, T., Arul, K., Bird, H., et al. (2002). Anomia is simply a reflection of semantic and phonological impairments: Evidence from a case-series study. Aphasiology, 16, 56-82

Lambon Ralph, M. A., Patterson, K., Graham, N., Dawson, K., \& Hodges, J. R. (2003). Homogeneity and heterogeneity in mild cognitive impairment and Alzheimer's disease: A cross-sectional and longitudinal study of 55 cases. Brain, 126, 2350-2362. 
Lezak, M. (1976). Neuropsychological assessment. New York: Oxford University Press.

Marshall, J. C., \& Newcombe, F. (1973). Patterns of paralexia: A psycholinguistic approach. Journal of Psycholinguistic Research, 2, 175-199.

McCann, R. S., \& Besner, D. (1987). Reading pseudohomophones: Implications for models of pronunciation assembly and the locus of wordfrequency effects in naming. Journal of Experimental Psychology: Human Perception and Performance, 13, 14-24.

McCarthy, R. A., \& Warrington, E. K. (1986). Phonological reading: Phenomena and paradoxes. Cortex, 22, 359-380.

McCarthy, R. A., \& Warrington, E. K. (1990). Cognitive neuropsychology: A clinical introduction. San Diego, CA: Academic Press.

McCloskey, M., \& Caramazza, A. (1988). Theory and methodology in cognitive neuropsychology: A response to our critics. Cognitive Neuropsychology, 5, 583-623.

McKenna, P., \& Warrington, E. K. (1983). The Graded Naming Test. London: NFER.

Medler, D. A., Dawson, M. R. W., \& Kingstone, A. (2005). Functional localization and double dissociations: The relationship between internal structure and behavior. Brain and Cognition, 57, 146-150.

Mendez, M. F. (2002). Slowly progressive alexia. Journal of Neuropsychiatry and Clinical Neurosciences, 14, 84.

Miozzo, M., \& Gordon, P. (2005). Facts, events, and inflection: When language and memory dissociate. Journal of Cognitive Neuroscience, 17, 1074-1086.

Monsell, S., Patterson, K. E., Graham, A., Hughes, C. H., \& Milroy, R. (1992). Lexical and sublexical translation of spelling to sound: Strategic anticipation of lexical status. Journal of Experimental Psychology: Learning, Memory, and Cognition, 18, 452-467.

Mummery, C. J., Patterson, K., Price, C. J., Ashburner, J., Frackowiak, R. S. J., \& Hodges, J. R. (2000). A voxel-based morphometry study of semantic dementia: Relationship between temporal lobe atrophy and semantic memory. Annals of Neurology, 47, 36-45.

Neary, D., Snowden, J. S., Gustafson, L., Passant, U., Stuss, D., Black, S., et al. (1998). Frontotemporal lobar degeneration: A consensus on clinical diagnostic criteria. Neurology, 51, 1546-1554.

Nestor, P. J., Fryer, T. D., \& Hodges, J. R. (2006). Declarative memory impairments in Alzheimer's disease and semantic dementia. NeuroImage, 30, 1010-1020.

Noble, K., Glosser, G., \& Grossman, M. (2000). Oral reading in dementia. Brain and Language, 74, 48-69.

Parkin, A. J. (1993). Progressive aphasia without dementia: A clinical and cognitive neuropsychological analysis. Brain and Language, 44, 201-220.

Patterson, K., \& Behrmann, M. (1997). Frequency and consistency effects in a pure surface dyslexic patient. Journal of Experimental Psychology: Human Perception and Performance, 23, 1217-1231.

Patterson, K., Graham, N., \& Hodges, J. R. (1994). Reading in dementia of the Alzheimer's type: A preserved ability? Neuropsychology, 8, 395-407.

Patterson, K., \& Hodges, J. R. (1992). Deterioration of word meaning: Implications for reading. Neuropsychologia, 30, 1025-1040.

Patterson, K., \& MacDonald, M. C. (2006). Sweet nothings: Narrative speech in semantic dementia. In S. Andrews (Ed.), From inkmarks to ideas: Current issues in lexical processing (pp. 299-317). Hove, England: Psychology Press.

Patterson, K., Plaut, D. C., McClelland, J. L., Seidenberg, M. S., Behrmann, M., \& Hodges, J. R. (1996). Connections and disconnections: A connectionist account of surface dyslexia. In E. Ruppin (Ed.), Neural modelling of cognitive and brain disorders (pp. 177-199). Singapore: World Scientific.

Patterson, K., Ralph, M. A. L., Jefferies, E., Woollams, A., Jones, R., Hodges, J. R., \& Rogers, T. T. (2006). "Presemantic" cognition in semantic dementia: Six deficits in search of an explanation. Journal of Cognitive Neuroscience, 18, 169-183.
Patterson, K., Suzuki, T., Wydell, T., \& Sasanuma, S. (1995). Progressive aphasia and surface alexia in Japanese. Neurocase, 1, 155-165.

Plaut, D. C. (1995). Double dissociation without modularity: Evidence from connectionist neuropsychology. Journal of Clinical and Experimental Neuropsychology, 17, 291-321.

Plaut, D. C. (1997). Structure and function in the lexical system: Insights from distributed models of word reading and lexical decision. Language and Cognitive Processes, 12, 765-805.

Plaut, D. C. (2003). Interpreting double dissociations in connectionist networks. Cortex, 39, 138-141.

Plaut, D. C., McClelland, J. L., Seidenberg, M. S., \& Patterson, K. (1996). Understanding normal and impaired word reading: Computational principles in quasi-regular domains. Psychological Review, 103, 56-115.

Price, C. J., Gorno-Tempini, M. L., Graham, K. S., Biggio, N., Mechelli, A., Patterson, K., \& Noppeney, U. (2003). Normal and pathological reading: Converging data from lesion and imaging studies. NeuroImage, 20, S30-S41.

Rapp, B. (2001). The handbook of cognitive neuropsychology. Philadelphia: Psychology Press.

Raven, J. C. (1962). Coloured progressive matrices: Sets A, AB, B. London: Lewis.

Raymer, A. M., \& Berndt, R. S. (1996). Reading lexically without semantics: Evidence from patients with probable Alzheimer's disease. Journal of the International Neuropsychological Society, 2, 340-349.

Riddoch, M. J., \& Humphreys, G. W. (1993). The Birmingham Object Recognition Battery (BORB). London: Erlbaum.

Rogers, T. T., Hodges, J. R., Lambon Ralph, M. A., \& Patterson, K. (2003). Object recognition under semantic impairment: The effects of conceptual regularities on perceptual decisions. Language and Cognitive Processes, 18, 625-662.

Rogers, T. T., Ivanoiu, A., Patterson, K., \& Hodges, J. R. (2006). Semantic memory in Alzheimer's disease and the frontotemporal dementias: A longitudinal study of 236 patients. Neuropsychology, 20, 319-335.

Rogers, T. T., Lambon Ralph, M. A., Garrard, P., Bozeat, S., McClelland, J. L., Hodges, J. R., \& Patterson, K. (2004). Structure and deterioration of semantic memory: A neuropsychological and computational investigation. Psychological Review, 111, 205-235.

Rogers, T. T., Lambon Ralph, M. A., Hodges, J. R., \& Patterson, K. (2004). Natural selection: The impact of semantic impairment on lexical and object decision. Cognitive Neuropsychology, 21, 331-352.

Saffran, E. M. (1985). Lexicalisation and reading performance in surface dyslexia. In K. Patterson, J. C. Marshall, \& M. Coltheart (Eds.), Surface dyslexia: Neuropsychological and cognitive studies of phonological reading (pp. 53-71). London: Erlbaum.

Schwartz, M. F., Dell, G. S., Martin, N., Gahl, S., \& Sobel, P. (2006). A case-series test of the interactive two-step model of lexical access: Evidence from picture naming. Journal of Memory and Language, 54, 228-264.

Schwartz, M. F., Marin, O. S., \& Saffran, E. M. (1979). Dissociations of language function in dementia: A case study. Brain and Language, 7, 277-306.

Schwartz, M. F., Saffran, E. M., \& Marin, O. S. M. (1980). Fractionating the reading process in dementia: Evidence for word-specific print-tosound associations. In M. Coltheart, K. Patterson, \& J. C. Marshall (Eds.), Deep dyslexia (pp. 259-269). London: Routledge.

Seeley, W. W., Bauer, A. M., Miller, B. L., Gorno-Tempini, M. L., Kramer, J. H., Weiner, M., \& Rosen, H. J. (2005). The natural history of temporal variant frontotemporal dementia. Neurology, 64, 1384-1390.

Seidenberg, M. S., \& McClelland, J. L. (1989). A distributed, developmental model of word recognition and naming. Psychological Review, 96, 523-568.

Shallice, T. (1988). From neuropsychology to mental structure. Cambridge, England: Cambridge University Press.

Shallice, T., \& Warrington, E. K. (1980). Single and multiple component 
central dyslexic syndromes. In M. Coltheart, K. Patterson, \& J. C. Marshall (Eds.), Deep dyslexia (pp. 91-118). London: Routledge.

Shallice, T., Warrington, E. K., \& McCarthy, R. (1983). Reading without semantics. Quarterly Journal of Experimental Psychology: Human Experimental Psychology, 35(A), 111-138.

Shibahara, N., Zorzi, M., Hill, M. P., Wydell, T., \& Butterworth, B. (2003). Semantic effects in word naming: Evidence from English and Japanese Kanji. Quarterly Journal of Experimental Psychology: Human Experimental Psychology, 56(A), 263-286.

Silveri, M. C., \& Colosimo, C. (1995). Hypothesis on the nature of comprehension deficit in a patient with transcortical mixed aphasia with preserved naming. Brain and Language, 49, 1-26.

Snowden, J. S., Goulding, P. J., \& Neary, D. (1989). Semantic dementia: A form of circumscribed cerebral atrophy. Behavioural Neurology, 2, $167-182$.

Strain, E., \& Herdman, C. M. (1999). Imageability effects in word naming: An individual differences analysis. Canadian Journal of Experimental Psychology, 53, 347-359.

Strain, E., Patterson, K., Graham, N., \& Hodges, J. R. (1998). Word reading in Alzheimer's disease: Cross-sectional and longitudinal analyses of response time and accuracy data. Neuropsychologia, 36, $155-171$

Strain, E., Patterson, K., \& Seidenberg, M. S. (1995). Semantic effects in single-word naming. Journal of Experimental Psychology: Learning, Memory, and Cognition, 21, 1140-1154.

Strain, E., Patterson, K., \& Seidenberg, M. S. (2002). Theories of word naming interact with spelling-sound consistency. Journal of Experimental Psychology: Learning, Memory, and Cognition, 28, 207-214.

Van Orden, G. C., Jansen op de Haar, M. A., \& Bosman, A. M. T. (1997). Complex dynamic systems also predict dissociations, but they do not reduce to autonomous components. Cognitive Neuropsychology, 14, 131-165.

Van Orden, G. C., Pennington, B. F., \& Stone, G. O. (2001). What do double dissociations prove? Cognitive Science, 25, 111-172.

Ward, J., Stott, R., \& Parkin, A. J. (2000). The role of semantics in reading and spelling: Evidence for the "summation hypothesis." Neuropsychologia, 38, 1643-1653.

Warrington, E. K. (1975). The selective impairment of semantic memory. Quarterly Journal of Experimental Psychology, 27, 635-657.

Warrington, E. K. (1984). Recognition Memory Test. Windsor, England: NFER-Nelson.

Wechsler, D. A. (1987). Wechsler Memory Scale-Revised. New York: Psychological Corporation.

Weekes, B., \& Coltheart, M. (1996). Surface dyslexia and surface dysgraphia: Treatment studies and their theoretical implications. Cognitive Neuropsychology, 13, 277-315.

Weekes, B. S., \& Robinson, G. (1997). Semantic anomia without surface dyslexia. Aphasiology, 11, 813-825.

\section{Appendix A}

\section{Surface List Words}

The following stimuli were used to assess the reading performance of both the lesioned triangle model and all semantic dementia patients in this study. Responses classified as legitimate alternative reading of components (LARC) errors are provided where appropriate in the version of DISC phonemes used by Plaut et al. (1996).

\begin{tabular}{|c|c|c|c|}
\hline Regular & LARC & Exception & LARC \\
\hline \multicolumn{4}{|c|}{ High frequency } \\
\hline air & & are & $\mathrm{Ar}$ \\
\hline black & & blood & blUd, blud \\
\hline Board & & both & boT, $b^{\wedge} \mathrm{T}$ \\
\hline brown & brOn & broad & brOd \\
\hline cost & $\mathrm{kOst}, \mathrm{k}^{\wedge} \mathrm{st}$ & come & $\mathrm{kOm}$ \\
\hline dark & & do & $\mathrm{dO}$ \\
\hline days & & does & $\mathrm{dOz}, \mathrm{dUz}$ \\
\hline did & & done & dOn, don \\
\hline down & & door & \\
\hline feel & & four & fWr, fUr \\
\hline food & fud, $\mathrm{f}^{\wedge} \mathrm{d}$ & front & frant, frOnt \\
\hline free & & full & $\mathrm{f}^{\wedge} 1$ \\
\hline girl & & give & gIv \\
\hline goes & $\mathrm{g}^{\wedge} \mathrm{z}, \mathrm{gUz}$ & gone & $\mathrm{gOn}, \mathrm{g}^{\wedge} \mathrm{n}$ \\
\hline green & & great & grEt, gret \\
\hline had & & have & hAv \\
\hline hand & & head & $\mathrm{hEd}$ \\
\hline hear & hAr & heard & hErd \\
\hline heat & hAt, het & heart & hErt \\
\hline home & $\mathrm{h}^{\wedge} \mathrm{m}$ & learn & lErn \\
\hline land & & love & $1 \mathrm{Ov}, 1 \mathrm{Uv}$ \\
\hline
\end{tabular}




\begin{tabular}{|c|c|c|c|}
\hline Regular & LARC & Exception & LARC \\
\hline leave & & month & $\operatorname{man} T$ \\
\hline mouth & mUT & most & most, $\mathrm{m}^{\wedge} \mathrm{st}$ \\
\hline much & & move & $\mathrm{mOv}, \mathrm{m}^{\wedge} \mathrm{v}$ \\
\hline must & & none & nOn, non \\
\hline nine & & once & ans \\
\hline off & & one & On, on \\
\hline per & & own & Wn \\
\hline same & & put & $\mathrm{p}^{\wedge} \mathrm{t}$ \\
\hline saw & & said & sAd, s@d \\
\hline sense & & says & $\mathrm{sAz}$ \\
\hline south & sUT & some & $\mathrm{sOm}$ \\
\hline stock & & source & sWrs \\
\hline too & & stood & $\mathrm{stUd}, \mathrm{st}^{\wedge} \mathrm{d}$ \\
\hline trial & & truth & $\operatorname{tr}^{\wedge} \mathrm{T}$ \\
\hline well & & two & to \\
\hline which & & where & wEr, wur \\
\hline while & & whom & ham, $\mathrm{h}^{\wedge} \mathrm{m}$ \\
\hline whole & & whose & hOz, hOs \\
\hline will & & world & wOrld \\
\hline with & & would & wOld \\
\hline year & yAr & your & yWr, yUr \\
\hline
\end{tabular}

\begin{tabular}{|c|c|c|c|}
\hline \multirow{2}{*}{\multicolumn{2}{|c|}{$\begin{array}{l}\text { breach } \\
\text { broach }\end{array}$}} & breast & brEst \\
\hline & & brooch & brUC \\
\hline carve & & caste & kAst \\
\hline \multicolumn{2}{|l|}{ cliff } & climb & klim \\
\hline \multicolumn{2}{|l|}{ coil } & comb & kUm, kam \\
\hline couch & $\mathrm{k}^{\wedge} \mathrm{C}$ & cough & $\mathrm{kW}, \mathrm{kO}, \mathrm{k}^{\wedge} \mathrm{f}, \mathrm{kU}$ \\
\hline \multicolumn{2}{|l|}{ ditch } & dost & dOst, dost \\
\hline \multirow{2}{*}{\multicolumn{2}{|c|}{$\begin{array}{l}\text { dodge } \\
\text { dole }\end{array}$}} & dough & $\mathrm{dW}$, dof, dU, $\mathrm{d}^{\wedge} \mathrm{f}$ \\
\hline & & dread & $\mathrm{drEd}$ \\
\hline \multicolumn{2}{|l|}{ gaze } & gauge & gOrj \\
\hline \multicolumn{2}{|l|}{ gland } & ghoul & $\mathrm{gWl}, \mathrm{gOl}$ \\
\hline \multirow{2}{*}{\multicolumn{2}{|c|}{$\begin{array}{l}\text { glide } \\
\text { hoarse }\end{array}$}} & glove & glOv, glUv \\
\hline & & hearth & hurT \\
\hline \multicolumn{2}{|l|}{ hoop } & hood & hUd, h^d \\
\hline hoot & hut & hook & hUk \\
\hline \multicolumn{2}{|l|}{ ledge } & leapt & lEpt \\
\hline \multicolumn{2}{|l|}{ mince } & mauve & mOrv \\
\hline \multicolumn{2}{|l|}{ mug } & mould & mud \\
\hline \multicolumn{2}{|l|}{ mulch } & mourn & $\mathrm{mWrn}$ \\
\hline \multicolumn{2}{|l|}{ munch } & mow & $\mathrm{mW}$ \\
\hline pare & par & pear & $\mathrm{pEr}$ \\
\hline pleat & plAt, plet & plaid & plAd, pled \\
\hline pork & purk & poll & pal \\
\hline pray & & pour & pWr, pUr \\
\hline sag & & scarce & skars \\
\hline saint & & seize & sAz \\
\hline scribe & & sew & sU, syU \\
\hline shout & & shove & SOv, SUv \\
\hline snatch & snaC & sieve & $\mathrm{sEv}$ \\
\hline sour & sOr, sUr & soot & sUt \\
\hline sparse & sparz & sponge & spanj \\
\hline stack & & stead & stEd \\
\hline starch & & steak & stEk \\
\hline swell & & suave & swAv, sw@v, s^Av \\
\hline swerve & & suede & sWed \\
\hline swoop & & swear & swEr \\
\hline trance & & tread & $\operatorname{trEd}$ \\
\hline truce & & trough & $\operatorname{tr} \mathrm{W}, \operatorname{trO}, \operatorname{tr}^{\wedge} \mathrm{f}, \operatorname{tr} \mathrm{U}$ \\
\hline vale & & vase & vAz, vAs \\
\hline wipe & & womb & wam, wOm \\
\hline wisp & & wool & wUl \\
\hline yeast & yest & yearn & \\
\hline
\end{tabular}




\section{Appendix B}

\section{Surface List Nonwords}

The following stimuli were used to assess the reading performance of both the lesioned triangle model and a subset of semantic dementia patients in this study. Acceptable pronunciations are provided for each string in the version of DISC phonemes used by Plaut et al. (1996).

\begin{tabular}{|c|c|c|c|}
\hline Nonword & Pronunciations & Nonword & Pronunciations \\
\hline kead & kEd, ked & dut & $\mathrm{d}^{\wedge} \mathrm{t}$, dut \\
\hline larp & larp, 1Orp & nasp & $\mathrm{n} @ \mathrm{sp}$, nasp \\
\hline fove & $\mathrm{fOv}, \mathrm{f}^{\wedge} \mathrm{v}, \mathrm{fUv}$ & frowl & frWl, frOl \\
\hline haid & hAd, hed, h@d & gamp & g@mp, gamp \\
\hline rint & rint, rInt & neath & nET, neT \\
\hline gorth & gOrT, gurT & pash & $\mathrm{p} @ S, p o S$ \\
\hline nall & nol,n@1 & pook & puk, pUk \\
\hline mive & mIv, miv & lon & lan, $1^{\wedge} \mathrm{n}$ \\
\hline bross & bros, brOs & hinth & hInT, hint \\
\hline pome & $\mathrm{pOm}, \mathrm{p}^{\wedge} \mathrm{m}$ & fost & fOst, fost, $\mathrm{f}^{\wedge} \mathrm{st}$ \\
\hline reast & rEst, rest & pown & pOn, pWn \\
\hline bood & bUd, bud, $b^{\wedge} d$ & tolf & tolf, tulf \\
\hline hont & $\mathrm{h}^{\wedge} \mathrm{nt}, \mathrm{hOnt}$, hant & roul & rOl, rWl, rUl \\
\hline nush & $\mathrm{n}^{\wedge} \mathrm{S}, \mathrm{nuS}$ & chone & $\mathrm{COn}, \mathrm{C}^{\wedge} \mathrm{n}, \mathrm{Con}$ \\
\hline mave & mAv,m@v & heaf & hEf, hef \\
\hline sull & $\mathrm{s}^{\wedge} 1$, sul & voe & $\mathrm{vO}, \mathrm{vU}$ \\
\hline gow & $\mathrm{gW}, \mathrm{gO}$ & houch & $\mathrm{hWC}, \mathrm{h}^{\wedge} \mathrm{C}$ \\
\hline trear & trEr, trAr & toth & toT, tOT, $\mathrm{t}^{\wedge} \mathrm{T}$ \\
\hline doad & $\mathrm{dOd}$, dod & goot & $\mathrm{gUt}$, gut \\
\hline sonk & soNk, $s^{\wedge} \mathrm{Nk}$ & deak & $\mathrm{dEk}, \mathrm{dAk}$ \\
\hline
\end{tabular}

Received January 13, 2006

Revision received November 14, 2006

Accepted November 15, 2006 